\title{
Effect of Temperature and Heating Rate on Product Distribution from the Pyrolysis of Sugarcane Bagasse in a Hot Plate Reactor
}

\author{
Jorge Montoya ${ }^{1}$, Brennan Pecha ${ }^{2}$, David Roman ${ }^{1}$, Farid Chejne Janna ${ }^{1 *}$, Manuel Garcia-Pérez ${ }^{2 *}$ \\ ${ }^{1}$ Facultad de Minas, Universidad Nacional de Colombia, Colombia. \\ ${ }^{2}$ Washington State University, Pullman, WA 99164, USA. \\ (Paper to be submitted to the Journal of Analytical and Applied Pyrolysis)
}

\begin{abstract}
This paper reports studies on the film pyrolysis of sugarcane bagasse in an electrically heated hot plate reactor. The new experimental set up used is described. The bagasse studied was ground to particle sizes less than $37 \mu \mathrm{m}$ (mesh 400) and was mixed with water to form the paste to be used to form the biomass film (10 mg of sugarcane bagasse distributed evenly on a steel plate, $60 \mu \mathrm{m}$ thick). All the tests were conducted under vacuum (150 mbar). The effect of heating rate (between 5 and $1200{ }^{\circ} \mathrm{C} / \mathrm{s}$ ) and final temperatures (between 250 and $650{ }^{\circ} \mathrm{C}$ ) on product yields (permanent gases, water, light volatile, pyrolytic lignin, sugars and char) were studied. The yield of fragmentation and dehydration products increased as heating rates augment. The effect of heating rate is only important till $100{ }^{\circ} \mathrm{C} / \mathrm{s}$, no significant changes in product yields are observed at higher heating rates. Bio-oils enriched in lignin and sugars oligomers were obtained at high temperatures and heating rates. These results suggest that good yields of fermentable sugars may be obtained in pyrolysis reactors working at intermediary pyrolysis conditions.
\end{abstract}

Keywords: Fast Pyrolysis, Intermediate Phase Liquid, Bubbles, distribution function, Pyroprobe. 
Corresponding Authors:

Manuel Garcia-Perez

Associate Professor

Department of Biological Systems Engineering

Washington State University

Phone: 509-335-7758

e-mail: mgarcia-perez@wsu.edu
Farid Chejne Janna

Associate Professor

Escuela de Procesos y Energía

Universidad Nacional de Colombia

Phone: + 5745255333

e-mail: fchejne@una.edu.co 


\section{Introduction}

The sugarcane industry generates 100 tons of bagasse per 1000 tons of sugarcane processed [1]. This material is typically combusted at the mills for steam or power production. Sugarcane bagasse contains high amounts of volatile material (about 80 wt.\% DAF) [2]. This can be an excellent feedstock to produce value-added compounds via fast pyrolysis [3]. The final product distribution of fast pyrolysis depends on reactor operating conditions (temperature, pressure, gas flow entrainment, and reactor type) and on feedstock characteristics (particle size, nature of biomass material, and mineral content) [4-7]. The main targeted product of fast pyrolysis is a viscous polar liquid with high acidity known as bio-oil [8-12]. Pyrolysis reactors are typically characterized as "fast" or "slow" depending on the heating rate. At high heating fluxes (0.1-1.0 $\mathrm{MW} \mathrm{m}^{-2}$ [13]) it is possible to obtain bio-oil yields between 40 and 70 wt. \%. Much lower bio-oil yields (between 20 and 50 wt. $\%)$ have been reported at lower heating rates [14-16]. However, the exact heating rate at which the transition between slow and fast pyrolysis happens is unknown. There are several criteria to characterize pyrolysis reactors [17]. Some of them relates to the kind of reactor (fixed bed, fluid bed, ablative), dominant heat transfer mechanism (convection, radiation, conduction), final temperature and particle size used. In fast pyrolysis reactors, it is common to assume sample temperature equal to reactor temperature (Biot<0.1). On an industrial scale, high heating rates are typically achieved in fluidized bed reactors with particle sizes between 0.5 and $2 \mathrm{~mm}[4,6]$. These tests are typically conducted between 500 and $600{ }^{\circ} \mathrm{C}[14,18]$. There are many parametric studies on the effect of reaction conditions in fluidized bed reactors on the yield $[8,9,13,16,19-30]$ and composition of pyrolysis oils $[6,31-36]$.

Several devices have been developed to study thermochemical reactions at low and high heating rates: wire mesh reactor, hot plate reactor, TGA, Py-GC/MS, radiant lamp, shock tube, Curie point reactor, magnetic induction reactor, pulse reactors, laser ablative reactor, micro-fluidized bed reactor and torch reactor [37-45]. Heated grid reactors (wire mesh reactors) [1,38-45] are popular to study thermochemical reactions at high heating rates $\left(>1000{ }^{\circ} \mathrm{C} / \mathrm{s}\right.$ ). These devices typically operate with small particles (between 100 and 150 $\mu \mathrm{m})$ and pressures between 2 mbar [39] and 50 bar [42]. Py-GC/MS is also used to study 
reactions under high heating rates. This technique allows the direct analysis of light volatile compounds but is not capable of analyzing heavy oligomeric compounds [46-49]. Some Py-GC/MS systems can be modified to collect bio-oil, char and permanent gases for further analysis [50, 51]. Modified pyro-probes have also been used in microexplosion visualization studies [50]. Lede [52-54] developed devices heated by radiant flash radiation (Xenon arc lamps). The advantages of these systems is that it is possible to focus the radiation directly on the surface of the solid while keeping the gas and reactor walls cold. These characteristics are important to minimize secondary reactions. Pyrolysis reactors based on laser ablation and magnetic heat induction have also been also developed [45,5559]. Thermo balances are the most popular devices to study pyrolysis of solid materials, but are limited to low heating rates $\left(\max 100{ }^{\circ} \mathrm{C} / \mathrm{min}\right)$. More information on these devises can be found elsewhere [37, 60, 61]. Most of existing designs have limitations derived from the size of the biomass sample employed, heating rate that can be achieved or by the method used to analyze products.

Thus, the main goal of this paper is to describe a new analytical hot plate pyrolysis reactor and to use this experimental set up to study the effect of final pyrolysis temperature and heating rates on the yield of sugarcane bagasse pyrolytic products.

\section{Materials and Methods}

\subsection{Hot Plate Reactor configuration}

A schematic representation of the reactor used is shown in Figure 1.The body of the reactor is made of stainless steel 304, schedule 40. Two copper electrodes were connected to the steel plate $(6 \times 4 \times 0.45 \mathrm{~mm})$. In the top reactor cover a $\mu$-Epsilon CT SF 25pyrometer, spectral range $8 \mu \mathrm{m}-14 \mu \mathrm{m}, 25$ was installed to measure the temperature on the surface of the steel sheet. A laterally connected 1/4 NPT fitting connects a DRUCK-DPI 104 pressure sensor to record pressure changes (error of 0.07 mbar). A thermocouple type $\mathrm{K}(0.6 \mathrm{~mm}$ thickness) was installed $3 \mathrm{~cm}$ above the plate to record the temperature of the gas phase. 
The connection indicated by the number 5 in Figure 1 is coupled to a vacuum pump (Pfeiffer MVP 006-4) to reduce pressure to 150 mbar.

\section{Figure 1.}

The outer shell of the reactor allows the addition of ice to maintain $0^{\circ} \mathrm{C}$ on reactor walls, minimizing possible side reactions. Two glass windows were installed on top of the cover for the pyrometer and for visualization. A heat exchanger was formed as a flat plate, in order to quickly collect reaction products generated. Inside the exchanger $\mathrm{CO}_{2}(\mathrm{~g})$ is expanded from a tank to keep the surface at $-10^{\circ} \mathrm{C}$. The reaction chamber has $51 / 4 \mathrm{NPT}$ connections. In one, a pressure sensor is installed. The remaining four are for input and output flows of nitrogen (passing through the reaction chamber) and $\mathrm{CO}_{2}$ flowing through the cold plate heat exchanger. Copper electrodes have a diameter of 1/8", and a length of 10 $\mathrm{cm}$. These pass through two cylindrical Teflon blocks for electrically isolating the housing and electrodes. A set of 4 copper plates ( 2 at each end, $5 \mathrm{~mm}$ thick, $5 \mathrm{~cm}$ long x $2 \mathrm{~cm}$ wide) are used as terminals to transmit power to the steel plate. The power system and control was designed in our laboratory facilities to have two independent circuits. The first supplies power to the reactor and the second records data and feeds information to the PID temperature control loop. Heating is accomplished by feeding AC current from a transformer $(10 \mathrm{~kW} 220 \mathrm{~V})$ to a $1 / 20$ power increaser. Figure 2 shows an overview of the control system.

\section{Figure 2.}

The heart of the control system is a 16-bit micro-processor responsible for controlling the temperature measured by the pyrometer. For reliable reading, the microprocessor record 50 times the temperature during the pyrometer response time $(10 \mathrm{~ms})$ and average it before any control action. This signal is sent every $10 \mathrm{~ms}$ to a computer using USB protocol. The temperature reading from the pyrometer is filtered by a digital filter (fourth order) to eliminate disturbances and noise caused by the electrical field generated at the electrodes. Finally, the software calculates the power to be delivered by the transformer using a PID control algorithm and sends the data to the micro-processor. The entire routine is performed 
every $10 \mathrm{~ms}$. At the maximum heating rate of this study $\left(1200{ }^{\circ} \mathrm{C} / \mathrm{s}\right)$ the system has a maximum temperature lag of $12{ }^{\circ} \mathrm{C}$ and an overall response time close to $10 \mathrm{~ms}$.

\subsection{Plate Temperature Calibration and Temperature Distribution}

Because of changes in emissivity of the surface of the steel sheet the measurements in the pyrometer have to be corrected. Calibration was done by adjusting the pyrometer emissivity to match the reading of a 0.022 " type $\mathrm{K}$ thermocouple (Omega). The plate was heated at 50 ${ }^{\circ} \mathrm{C} / \mathrm{s}$ and held at final temperature for $2 \mathrm{~min}$ between 100 and $800{ }^{\circ} \mathrm{C}$. Readings with the thermocouple and pyrometer were made in the central point (1 in Figure 3).

\section{Figure 3.}

The temperature in the biomass film was also measured by inserting a standard thermocouple type $\mathrm{K}$ chal 0.022 " inside the film. These additional experiments, are made to validate the hypothesis of Biot $<0.1$, and confirm that the temperature of the film biomass is the same as that registered on the surfaces of the steel sheet. These hypotheses were confirmed. The temperature distribution was checked recording 2 videos with thermal camera FLIR E60, one video at $50^{\circ} \mathrm{C} / \mathrm{s}$ and $\mathrm{Tf}=600^{\circ} \mathrm{C}$, the second at $200^{\circ} \mathrm{C} / \mathrm{s}$ and $\mathrm{Tf}=$ $400^{\circ} \mathrm{C}$. (see figure 8 )

\subsection{Materials}

Sugarcane bagasse was obtained from the sugarcane mill Risaralda, Colombia ( $4{ }^{\circ} 53$ '48 "N $75^{\circ} 53$ '02 "O), ground in a micro-hammer mill (IKA MF-10 3, $500 \mathrm{rpm}$ ), and sieved with 250 mesh (63 microns). In Table 1, the physicochemical characterization of this raw material and the methods used for compositional analyzes are shown. The composition of the ash was analyzed by ICP-MS Agilent 7 900, following the EPA 6020 protocol. The content of silica $\left(\mathrm{SiO}_{2}\right)$ was determined by XRF Bruker Tiger S8.

\section{Table 1.}

\subsection{Sample preparation}


Biomass films were prepared by suspending finely ground sugarcane bagasse (Figure 4A) in distilled water. The suspension is prepared with a solids concentration of $10 \mathrm{wt}$. \%. A thin brush is dipped into the suspension of the biomass, and painted over the central strip (63 mm long) of a steel plate $(6 \mathrm{~cm} \times 4 \mathrm{~cm} \times 0.45 \mathrm{~mm})$ (Figure 4B). The water from the suspension was removed by drying the sheet in a Mettler Toledo moisture balance (HB 34) under halogen slowly at $80{ }^{\circ} \mathrm{C}$. The resulting dry film of biomass adhered to the plate surface is shown in Figure 4C. To confirm the thickness of the biomass on the surface of the sheet, the edge was imaged with an optical microscope at $100 \mathrm{X}$ [62]. On average, in each experiment $10 \mathrm{mg}$ of bagasse was applied. The weight of the impregnated biomass is obtained by difference between the weight of the steel sheet before and after being impregnated with dry biomass.

\section{Figure 4.}

The distribution of biomass in the plate was examined with a Wild M3 stereoscope. Direct views of biomass objectives between 10X/21B with 0.6-1-1.6-2.5-4 magnification and image were made last seen $20 \mathrm{X}$ under a Nikon Eclipse TE-200 microscope, in order to see the distribution of biomass. Tests were performed to determine the effect of the amount of mass and hold time on the yield of char obtained and thus verify kinetic control conditions and reaction time. Figure 5 shows the distribution of the impregnated biomass on the steel sheet at various magnifications. From the chart (A) - (F) a fairly smooth surface with very few irregularities is observed.

\section{Figure 5.}

\subsection{Run Sequence}

Each experiment was performed in triplicate to ensure reproducibility. The weight of the steel plates was recorded before and after impregnation and drying with a Mettler Toledo analytical balance (XS205DU, $\mathrm{d}=0.01 \mathrm{mg}$ ). On average $10 \mathrm{mg}$ bagasse was deposited on the central part of the plate where there is homogenous temperature (reaction area of $1 \mathrm{~cm} \mathrm{x}$ $4 \mathrm{~cm}$ ) (see Figure 4). The plate is then clamped between the two electrodes. The reactor is sealed and ice is added around the outer casing to cool the outer walls of the reactor. Nitrogen (>99.996\% purity) is fed for 2 minutes at a rate of $5 \mathrm{~L} / \mathrm{min}$ to remove any air contained within the reactor. The vacuum pump evacuates nitrogen until the absolute 
pressure was 150 mbar. The software is set for heating rates between 5 and $1200{ }^{\circ} \mathrm{C} / \mathrm{s}$ and final temperature between 250 and $650{ }^{\circ} \mathrm{C}$. The heat exchanger is chilled using $\mathrm{CO}_{2}$ until the outlet temperature is $-10{ }^{\circ} \mathrm{C}$. At the beginning and end of each experiment the gas temperature and pressure are recorded. At the end of each experiment, the ice casing is removed, the $\mathrm{CO}_{2}$ cooling valve closed, and the reactor is brought to room temperature. After reaching room temperature (measured by the thermocouple mounted inside the reactor), the reactor is pressurized to just above 1 bar using nitrogen.

\subsection{Permanent gases}

The gas sample is taken into a $200 \mathrm{ml}$ Tedlar bag through valve 5 (see Figure 1) and is analyzed using a $\mu$-GC (Agilent 3000) with two independent channels. The first contains a Molsieve $5{ }^{\circ} \mathrm{A} 10 \mathrm{~m}$ capillary micro column to quantify $\mathrm{CO}, \mathrm{H}_{2}$ and $\mathrm{CH}_{4}$. The second module contains a micro-capillary column $10 \mathrm{~m}$ QP100 for the analysis of $\mathrm{CO}_{2}$. The carrier gas was helium for both channels with a 5.0 grade pressure in both columns at 20 psi. The suction time of the sample was $500 \mathrm{~ms}$ and the temperature in both ovens was maintained at $50{ }^{\circ} \mathrm{C}$ and the total analysis time is $3 \mathrm{~min}$. The chemical composition of the generated species were normalized in a nitrogen free base. Gas yield was estimated according to:

$$
\text { Gas Yield }\left(\% \frac{w}{w}\right)=100 \sum_{i=C O, \mathrm{CH}_{4}, \mathrm{CO}_{2}, \mathrm{H}_{2}}^{\mathrm{n}=4} \frac{\left(\mathbf{P}_{\text {after experiment }}-\mathbf{P}_{\text {before experiment }}\right) \frac{\mathbf{V}_{\text {reactor }}}{\mathbf{R T}_{\text {room }}} \mathbf{M w}_{\mathrm{i}}\left(\frac{\% \mathrm{~mol}_{\mathbf{i}}}{\mathbf{1 0 0}}\right)}{\mathbf{m}_{\text {biomass }}}
$$

Where $\mathrm{P}_{\text {after experiment }}$ and $\mathrm{P}_{\text {before experiment }}$ are the pressure in gas phase after and before each experiment (after the gas phase is a room temperature- $\mathrm{T}_{\text {room }}$ ), $\mathrm{Mw}_{\mathrm{i}}$ and $\% \mathrm{~mol}_{\mathrm{i}}$ are the molecular weight and mol fraction of specie $i$.

The final yield of each chemical species in the gas phase is determined with the total estimated yield and their respective normalized mole fractions (without nitrogen). The micro-GC was calibrated using certified mixtures of gases, in concentration ranges 0,100 , 200, 400, $800 \mathrm{ppm}$. The reactor volume was $897 \mathrm{ml}$. It was measured filling the reactor with water. 


\subsection{Bio-oil}

Because the diffusion of gases in vacuum is high, part of the bio-oil is condensed through all internal walls of the reactor, making it quite difficult to make a full recovery. Thus the bio-oil yield was determined by difference from the overall mass balance. A bio-oil sample condensed on the surface of the condenser was collected with quartz gauze, the weight of the gauze before and after collecting the sampling was recorder to estimate the mass for the sample. The bio-oil collected was dissolved in methanol and the resulting solution analyzed by GC/MS. The yield of the individual condensable species was calculated by multiplying their mass fraction in the bio-oil by the bio-oil yield.

Analysis of the condensable species, was made with a spectrometer Shimadzu QP 2010 using a capillary column Shrxi-MS of $0.25 \mathrm{~mm} \mathrm{ID,} 30 \mathrm{~m}$ long and $0.25 \mu \mathrm{m}$ stationary phase. The chromatograph oven was programmed with two temperature ramps beginning at $50{ }^{\circ} \mathrm{C}$ and heated at $10{ }^{\circ} \mathrm{C} / \mathrm{min}$ to $250{ }^{\circ} \mathrm{C}$, then at $20^{\circ} \mathrm{C} / \mathrm{min}$ to $320{ }^{\circ} \mathrm{C}$ with a holding time of $20 \mathrm{~min}$. The flow of carrier gas is $\mathrm{He}$ at $54 \mathrm{~L} / \mathrm{min}$, power of $0.1 \mathrm{kV}$ filament, split ratio 1 , injection volume $1 \mu$ l. The sample was injected into an injection port at $250{ }^{\circ} \mathrm{C}$. Before and after each injection the syringe washes five times with methanol. Calibration solutions were prepared with 5 different mass fractions of selected pyrolysis products (levoglucosan, 5-HMF, furan, formic acid, acetic acid, acetoin, glycoaldehyde, furfuryl alcohol, phenol, eugenol, vanillin, naphthalene, pyrocatecol, benzofuran and water). The compounds used for calibration were all analytical grade purities greater than 98 wt. \%. The moisture content was determined by quantifying the ion $\mathrm{m} / \mathrm{z} 18$ by mass spectrometry using a method described elsewhere [63]. The water mass fraction results

were validated by comparing the results obtained by GC/MS for samples with those obtained by Karl Fisher titration. Identification of each species was achieved knowing the retention time of each compound and comparing the spectra with those reported by the NIST database library.

Anhydro-sugar analysis was performed with a Varian ProStar HPLC (refractive index detector, Aminex HPX-87H column). The furnace was maintained at $80^{\circ} \mathrm{C}$ throughout the 
analysis with nano-pure water $(18 \mathrm{mS})$ (flow rate: $2 \mathrm{ml} / \mathrm{min}$ ). The injection volume was 40 $\mu$ L.Calibration curves were made for celotriosan, cellobiosan, 1,6 AGF, 1.4-3.6 DGP, levoglucosenone with 4 mass fraction levels.

An important fraction of bio-oil is oligomeric lignin (also known as pyrolytic lignin), which can be up to 10 wt. \% of bio-oil [64]. The yield of oligomeric lignin was determined by a modified UV fluorescence methods [64] calibrated with a pyrolytic lignin obtained by cold water precipitation. Briefly, $1 \mathrm{~L}$ of bio-oil obtained from the fast pyrolysis of sugarcane bagasse (particle size $1 \mathrm{~mm}$, fluidized bed reactor at $500{ }^{\circ} \mathrm{C}$, with flow biomass feed 10 $\mathrm{kg} / \mathrm{h}$, entraining gas flow $50 \mathrm{~L} / \mathrm{min}$ ) was precipitated in cold water [2]. The lignin oligomeric fraction collected by filtration was used to prepare standard solutions in methanol (concentrations between 0.04 to $0.5 \mathrm{ppm}$ for quantification of pyrolytic lignin yield (these low concentrations prevent self-absorption effects and redshift). The methanol solutions were analyzed on a Perkin Elmer LS 55 spectrofluorometer with a quartz cell of 1 $\mathrm{cm}$ nominal length. Data were obtained in synchronous mode with an energy gap of 2800 $\mathrm{cm}^{-1}$ and a scan speed of $50 \mathrm{~nm} / \mathrm{min}$. Each spectrum corresponds to the average of 3 scans. The content of lignin was calculated using the calibration curve obtained with the pyrolytic lignin separated from the bio-oil produced in the fluidized bed [2].

\subsection{Char}

Char in these experiments is defined as the carbonaceous material remaining after each experimental test. The biochar yield was determined by weighing the steel sheet with a final carbonaceous material, and knowing the initial weight of the biomass. The morphology of some char samples was studied using SEM (ZEISS model EVO MA 10 with a tungsten filament, Oxford Instruments X-act detector coupled to an EDX spectrometer). Before each analysis the samples were gold sputter coated (40 s, $5 \mathrm{~mA})$. EDX analysis was used to estimate the presence of mineral material through the sample. 


\section{Results and Discussion}

\subsection{Temperature Calibration and Distribution}

To perform thermochemical reaction studies, the temperature of the sample and the experimental set up need to be known. The fit between the thermocouple temperature measured at the midpoint of the steel sheet and the uncalibrated pyrometer (emissivity: 1) is shown in Figure 6-A. The average temperature difference between the uncalibrated pyrometer and the thermocouple is $90^{\circ} \mathrm{C}$. The curve shown in Figure 6 was used to correct the measurements obtained with the pyrometer. The corrected values of pyrometer temperature were compared with the melting point of known metals with good agreements (see Figure 6B).

\section{Figure 6.}

The temperature distribution on the steel plate is shown in Figure 7. The central strip of $1 \mathrm{x}$ $4 \mathrm{~cm}$ (central strip of Figure 7-A) is the hottest; the average temperature throughout this range is $383{ }^{\circ} \mathrm{C} \pm 7{ }^{\circ} \mathrm{C}$ with a difference of $23^{\circ} \mathrm{C}$ between the center and the edge. Figure 7$\mathrm{B}$ shows the thermal image at the same time point as data in Figure $7 \mathrm{~A}\left(400{ }^{\circ} \mathrm{C}\right)$. This image also shows even temperature distribution along the plate.

\section{Figure 7.}

The temperature distribution during heating is uniform in the central strip. Unfortunately, for higher rates the camera is not fast enough to follow the temperature.

\section{Figure 8.}

The temperature was uniform in the central area (see Figure 8).At lower heating rates (8A), the steel plate has more time to achieve a uniform distribution. The temperature distribution at moderate heating rates $\left(200^{\circ} \mathrm{C} / \mathrm{s}\right)$ was also uniform. In both cases the area with uniform 
temperature is $2 \mathrm{~cm} \times 4 \mathrm{~cm}$, in this way we assure that sample is heated at the same conditions in all points in the central frame. Similar results were obtained by Prins et al [45]. The author shows uniform temperature distribution in a Ni80/Cr20 foil of $1.6 \mathrm{~cm} \mathrm{x}$ $1 \mathrm{~cm} \times 0.1 \mathrm{~mm}$ heated at $725^{\circ} \mathrm{C}$ (between $300-600^{\circ} \mathrm{C} / \mathrm{s}$ ) with differences in temperature around $50^{\circ} \mathrm{C}$. The authors recommend the use of foils instead of meshes to assure uniform temperature distributions.

The next step was to evaluate the effect of biomass film loading on temperature measurements at different heating rates $\left(50,100\right.$ and $\left.500^{\circ} \mathrm{C} / \mathrm{s}\right)$. Figure 9 shows that variation between the loaded and unloaded plate is very small, indicating that biomass load has no effect on the temperature as recorded by the pyrometer. The temperature history, is practically the same between hot plate surface and biomass thin film surface. With amount of biomass loaded and spread over the plate, a very thin film is formed with very low resistance to the heat transfer by conduction. In other words the Biot number is small (Bi $<0.01)$. So, for practical purposes we can consider that the biomass sample and the plate surface temperatures are the same.

\section{Figure 9.}

\subsection{Impact of holding time and film thickness on char yield}

The study of the effect of particle thickness and hold time was determined at $500{ }^{\circ} \mathrm{C} / \mathrm{s}$ and $500{ }^{\circ} \mathrm{C}, 150$ mbar pressure (initial pressure), varying thicknesses of biomass between 29 $291 \mu \mathrm{m}$. Figure $-5 \mathrm{G}$ shows an optical microscope visualization of sugarcane bagasse films with thickness of $60 \pm 13$ microns.

Char yields obtained with different thicknesses (different mass) are shown in Figure 10A. Particles $<100$ microns produce the same char yields $(\approx 10 \mathrm{wt}$. \%). These results indicate that secondary reactions in liquid phase within the film (thickness $<100$ microns) do not alter char yield. It is valid for thickness $<100 \mu \mathrm{m}$. For thicker particles, there is a competitive mechanism between oligomers evaporation and reactions in liquid phase to produce secondary char [65-69]. For large particles (with lumen structures) the ejected 
aerosol are trapped within solid matrix by collision with cell walls [70] promoting secondary char formation. So we decided to conduct the rest of our experiments with films having an average thickness of $60 \pm 13$ microns. Figure 10B shows that the yield of char is the same for different hold times.

\section{Figure 10.}

\subsection{Species studied in these experiments}

In Table 2, the major compounds identified by GC-MS, GC- $\mu$, and HPLC are listed. The names of molecules, retention time, molecular ions, were identified by NIST library.

\section{Table 2.}

\subsection{Effect of Peak Temperature on the yield of volatile species detectable by GC/MS}

A parametric study was performed to determine the effects of temperature and heating rate on product yields (water, acetoin, acetaldehyde, formic acid, acetic acid, furfuryl alcohol). Two heating rates were used (5 and $1200{ }^{\circ} \mathrm{C} / \mathrm{s}$ ) and temperature between 177 to $677{ }^{\circ} \mathrm{C}$. Results are shown in Figure 11. Most of these products are mainly formed by fragmentation reactions, decarboxylation, and pyranose ring formation [42-44]. Furanose comes from cellulose and hemicellulose [67,71]. Yields of all these products increase with temperature in agreement with results in the literature [72,73]. At a lower heating rate $\left(5{ }^{\circ} \mathrm{C} / \mathrm{s}\right)$, the yields of these products are higher than at high heating rates $\left(1200{ }^{\circ} \mathrm{C} / \mathrm{s}\right)$. At low heating rates, the dehydration and crosslinking reactions in the solid phase or in the liquid intermediate are enhanced [67].

In this study, Glycoaldehyde has a maximum yield of 5 wt. $\%$ at $5^{\circ} \mathrm{C} / \mathrm{s}$. Paulsen et al. [62] found for fast pyrolysis of cellulose glycoaldehyde yield increases with temperature until being constant at $6.7 \mathrm{wt} . \%$ after $450{ }^{\circ} \mathrm{C}$. It has been reported that the presence of mineral material biomass, could reduce yields because mineral matter promotes fragmentation reactions and ring opening of the pyranose and furanose [71]. Similarly, yields of other 
light oxygenates such as acetoin, formic acid, acetic acid, furfuryl alcohol increase with temperature; this is in agreement with other investigations on fast pyrolysis of biomass [67,72-74]. Acetic acid can be formed by various reaction routes, mostly through deacetylation of hemicellulose at $300^{\circ} \mathrm{C}$ [71]; some also comes from rearrangement of the pyranose rings in cellulose $[75,76]$.

\section{Figure 11.}

The water yield (Figure 11A) increases with temperature, reaching a peak of $19.0 \mathrm{wt} . \%$ at the low heating rate, mostly due to enhanced crosslinking/dehydration reactions [77]. At high heating rates, the samples depolymerize mostly over $350{ }^{\circ} \mathrm{C}$, at these temperatures depolymerization reactions dominate over crosslinking reactions. At $500 \mathrm{~K}$ with $5{ }^{\circ} \mathrm{C} / \mathrm{s}$, the largest amounts of water are produced. At this temperature $\left(200-300{ }^{\circ} \mathrm{C}\right)$, hemicellulose is known to decompose and form water [75,78-80]. An important amount of water is also produced from the dehydration of cellulose primary products in the liquid intermediate [81]. Lignin is degraded in a wide temperature range $\left(300-500{ }^{\circ} \mathrm{C}\right)$; its main products are oligomers and phenols, but water can also be produced in small quantities [82]. Yields of Furan and 5-HMF (Figure 12) increase with temperature. These compounds are also released from fragmentation reactions (ring-openings of cellulosic pyranose and hemicellulosic furanose rings).

\section{Figure 12.}

The formation of 5-HMF is promoted by acid catalysis [83]. During pyrolysis the sugar rings open and reorganize to form new sugars such as fructose. According to recent paper of Le Brech, et al [84], light oxygenates as Furan, Methyl -glyoxal are produced by transglycolyzation/opening rings and dehydration reactions. Furanic compounds are observed by opening ring/ciclization of pyranose ring from xylan at $250-350^{\circ} \mathrm{C}$. Mettler et al. [75] found however that both 5-HMF and glycoaldehyde are primary reaction products of cellulose which are formed by breaking the glycosidic homolitic bonds and subsequently breaking pyranose rings. 5-HMF yields for fast pyrolysis of cellulose are typically in the range of 3-8.7 wt.\% (cellulose basis) $[62,85]$. Our results at high heating rates are lower (1 wt. $\%$ at $1200{ }^{\circ} \mathrm{C} / \mathrm{s}$ ). Both temperature and lignin content increase the yield of 5-HMF [49]. Zhang, et al.[73] found that lignin interactions has an effect on the performance of furans, 
increasing it $1.4 \mathrm{wt}$. \%, due to the presence of lignin-cellulose covalent bonds at carbon 6 in Pyranose ring.

Hemicellulose is another possible source of furanic molecules [79]. The interaction of hemicellulose and lignin furans increases its yield [73]. In our results furan yield increases with temperature, in correspondence with other studies [64,86]. Naphthalene is normally reported as a secondary or tertiary product. The formation of this compound may be accelerated by the catalytic effect of Fe (present in steel) [87]. The distribution of the main lignin monomeric products is shown in Figure 13.As temperature increases, yields of naphthalene, phenol, pyrocatechol, eugenol, vanillin, and benzofuran also increase. This is in agreement with the literature [72,73,88,89]. It has been reported that the primary products of lignin decomposition are high molecular weight oligomers and a smaller quantity of monomers [90-93]. At high heating rates, the residence time of these oligomers within the particle is low $(<2$ s) so the mono-phenolic yield is lower compared to low heating rates. The phenolic monomers are produced by both primary reactions of lignin and from the further degradation of the oligomers.

\section{Figure 13.}

\subsection{Lignin oligomers formation}

The UV fluorescence spectra of the bio-oil obtained at 300,400 and $600\left(500{ }^{\circ} \mathrm{C} / \mathrm{s}\right)$ are shown in Figure 14A. Two representative peaks are shown: Peak A is between 296-326 nm and peak B is between 326-380 nm. Tests with solutions of eugenol, vanillin, 1, 2, 3, trimethoxy benzene (single-ring phenols) in methanol at $4 \mathrm{ppm}$ showed that these peaks appear in between 280-290 nm. Levoglucosan barely shows any intensity at $280 \mathrm{~nm}$. The results shown in Figure 14 confirm that Peak B is mostly due to the presence of oligomeric compounds. Peak B, increases dramatically with temperature. This indicates the formation of high molecular weight compounds with more than two aromatic rings.

\section{Figure 14.}


Oligomers lignin phenols are known to be mixture of two to four aromatic rings (average molecular weights 500 Da [94], 645 Da [91]). Using DFT, researchers have concluded that excitation wavelength increases as rings grow to clusters of four, but beyond four rings there is no difference in the excitation wavelength (plateau) [92]. It is also important to mention that our experiments were conducted in vacuum, so it is possible that oligomers with high molecular weight quickly escape through vaporization or thermal ejection [64].

Figure 15 shows the yields of total oligomers obtained depending on the temperature and heating rate. The yield of lignin oligomers increases with heating rate and temperature. It is known that during pyrolysis lignin in the biomass is in a melt phase [95,96], in which bubbles are formed responsible for ejection of aerosols [69]. At higher temperatures and heating rates the intensity of bubble formation and micro explosion increased. This claims have been validated with pure liquids [97,98].

\section{Figure 15.}

\subsection{Temperature effect on anhydrosugar yields}

Figure 16 shows the distribution of levoglucosan (GC-MS) and total sugars determined by HPLC. The profile of identifiable sugars by HPLC shows only cellotriosan, cellobiosan in very small amounts (about $200 \mathrm{ppm}$ ) and 1,4:3,6 dianhydroglucopyranose (DGP). The levoglucosan yield averages $8.65 \mathrm{wt} . \%$ at high heating rates $\left(1200{ }^{\circ} \mathrm{C} / \mathrm{s}\right)$, and is double that obtained at low heating rates $\left(4.42 \mathrm{wt} . \%\right.$ at $\left.5{ }^{\circ} \mathrm{C} / \mathrm{s}\right)$. Biomasses with low content of mineral material can reach levoglucosan yields of between 8 and $18 \%$ wt. [89,96,99].

\section{Figure 16.}

At low heating rates, the temperature at which levoglucosan formation initiates, is approximately $277{ }^{\circ} \mathrm{C}$ (yield 1 wt. \%). Constant yield is achieved beyond $350{ }^{\circ} \mathrm{C}(623 \mathrm{~K})$. Levoglucosan boils at $292{ }^{\circ} \mathrm{C}$ [100]. The high molecular anhydrosugars content is low, indicating that they decomposed to low molecular weight sugars such as levoglucosan and

1,4:3,6 DGP. The final yield of levoglucosan is greater at high heating rates. Many researchers suggest the reduction in levoglucosan yield by effect of alkali cations, 
especially potassium. Alkaline metals can promote fragmentation and disproportiation reactions, thus causing increased of acetaldehyde, glyoxal and other light oxygenates. The alkali metals might inhibit the levoglucosan yield by capping the free ends groups of cellulose chain and thus avoiding the unzipping reactions continues. Some researchers have argued that the acid or alkali catalytic effect is enhanced by the ionic medium formed [101]. In this study there are two competing effects, first is the possible reduction in levoglucosan yield by catalytic effect of potassium, second one is the possible increase of levoglucosan yield by rapid remotion of levoglucosan favored by vacuum. The final result depend of which phenomena dominates. For instance for cellulose pyrolysis at $300^{\circ} \mathrm{C}[102]$, it has been observed $53 \%$ more levoglucosan at $1.5 \mathrm{mmHg}$ and $5 \% \mathrm{SbCl} 3$ in comparison with atmospheric pressure without catalyst. Likewise in cellulose impregnated with acid [103] during vacuum pyrolysis $(130 \mathrm{~Pa})$ at $2{ }^{\circ} \mathrm{C} / \mathrm{min}$ the levoglucosan yield increase, contrary to results at atmospheric pressure [104].

\subsection{Temperature effect over Permanent Gases}

Figure 17 shows the yields of permanent gases detected during pyrolysis of bagasse. The yield of carbon monoxide increases with temperature and remains constant after $773 \mathrm{~K}$ $\left(500{ }^{\circ} \mathrm{C}\right)$. Carbon monoxide comes primarily lignin decomposition at low temperatures (T $<500 \mathrm{~K})$. In lignin, $\mathrm{CO}$ is generated by fragmentation reactions of carbonyl and carboxyl groups attached to $\gamma$-carbons [105-107]. The $\alpha-\mathrm{O}-4$ and $\beta-\mathrm{O} 4$ bonds tend to fragment after $200{ }^{\circ} \mathrm{C}$ and $245{ }^{\circ} \mathrm{C}$ releasing $\mathrm{CO}$ and $\mathrm{CO}_{2}$ respectively. At high temperatures $(\mathrm{T}>773 \mathrm{~K})$, the source of CO is ether bond breaking 4-O-5 [105,108]. Hemicellulose decomposition at low temperatures $\left(\mathrm{T}<250{ }^{\circ} \mathrm{C}\right)$ produces $\mathrm{CO}_{2}[72,75]$ and char. At low heating rates, pyranose rings in the intermediate liquid phase release $\mathrm{CO}_{2}[64,67]$; this partly explains the decrease in yield with increasing heating rate. Similar results were obtained by Hoekstra et al. [39] pyrolyzing pinewood at $6,000{ }^{\circ} \mathrm{C} / \mathrm{s}$. At low heating rates, the majority of the $\mathrm{CO}_{2}$ is released before $600 \mathrm{~K}\left(327^{\circ} \mathrm{C}\right)$ with carbonyl and carboxyl decomposition of hemicellulose [85]. Lignin is another precursor of $\mathrm{CO}_{2}$, especially by decarboxylation reactions at low temperatures $\left(\mathrm{T}<300{ }^{\circ} \mathrm{C}\right)$. Lignin oligomers produce large amounts of $\mathrm{CO}_{2}$ [109], at high heating rates these oligomers rapidly leave the solid matrix of the biomass, thereby reducing their contribution to the production of $\mathrm{CO}_{2}$. 


\section{Figure 17.}

The yields of hydrogen and methane are quite low (<0.5 wt.\%), similar to other researchers [39]. Methane and hydrogen likely come from lignin [110]. Generally, it is observed that the effect of the heating rate is most dramatic for $\mathrm{CO}_{2}$.

\subsection{Temperature effect on char yield}

Figure 18 shows yields of char as a function of temperature at two heating rates. As the temperature increases, char yield decreases until $740 \mathrm{~K}\left(467{ }^{\circ} \mathrm{C}\right)$ at $1200{ }^{\circ} \mathrm{C} / \mathrm{s}$, and $673 \mathrm{~K}$ $\left(400{ }^{\circ} \mathrm{C}\right.$ ) at $5{ }^{\circ} \mathrm{C} / \mathrm{s}$. There is a difference of $25 \%$ in char yields produced at $1200^{\circ} \mathrm{C}$ and 5 ${ }^{\circ} \mathrm{C} / \mathrm{s}$, respectively. As the heating rate increases, char decreases dramatically. As discussed in the previous section, the content of oligomers and lignin anhydro-sugar increases with the heating rate due to rapid evaporation and aerosol ejection [77,90,99]. These oligomers are precursors of dehydration and crosslinking reactions which lead to the generation of char $[39,77,93]$.

Figure 18.

Morphological changes of biomass pyrolyzed at high $\left(1200{ }^{\circ} \mathrm{C} / \mathrm{s}\right)$ and low rates of heating $\left(5{ }^{\circ} \mathrm{C} / \mathrm{s}\right)$ and different temperatures $\left(300-500{ }^{\circ} \mathrm{C}\right)$ are presented in Figure 19. In addition, it shows the distribution of major minerals in the carbonaceous residue obtained at $1200{ }^{\circ} \mathrm{C} / \mathrm{s}$ and $500{ }^{\circ} \mathrm{C}$. At low temperatures $\left(300{ }^{\circ} \mathrm{C}\right)$, irrespective of the heating rate, no morphological changes were observed. From $500{ }^{\circ} \mathrm{C}$, both high and low heating rates are softening the solid matrix. Finally the spectrogram obtained by EDX $1200{ }^{\circ} \mathrm{C} / \mathrm{s}$ and $500{ }^{\circ} \mathrm{C}$, shows the distribution of minerals and carbon species present in the char analyzed. Spectrograms show that in the analyzed area, the ratio between the Si and the catalytically

active cations $(\mathrm{K}, \mathrm{Ca}, \mathrm{Mg}, \mathrm{Na}$ ) is very high, with a ratio of 60/1 (by fractions obtained by EDX).

\section{Figure 19.}

\subsection{Heating rate effect on main products yield at $500{ }^{\circ} \mathrm{C}$}


The effect of the heating rate on the yield of the main products analyzed for pyrolysis of bagasse at $500{ }^{\circ} \mathrm{C}$ are shown in Figure 20. It is clear that after $120{ }^{\circ} \mathrm{C} / \mathrm{s}$ we do not see any significant effect of the yield of the products studied.

\section{Figure 20.}

Above $100{ }^{\circ} \mathrm{C} / \mathrm{s}$, for most compounds, changes in yields are minimal. For heating rates below $100{ }^{\circ} \mathrm{C} / \mathrm{s}$, the oligomeric primary products can undergo secondary reaction. For heating rates at $100{ }^{\circ} \mathrm{C} / \mathrm{s}$, the secondary dehydration and crosslinking reaction in condensed stages seems to be minimized. In the range of heating rates used in this study, no major changes were observed in yields of hydrogen and methane, as seen by others [39]. With respect to $\mathrm{CO}_{2}$ and $\mathrm{CO}$, our results show a decrease in the yield of $\mathrm{CO}_{2}$ for heating rates above $100{ }^{\circ} \mathrm{C} / \mathrm{s}$. An important source of $\mathrm{CO}_{2}$ is the hemicellulose and cellulose via decarboxylation reactions of the acetyl groups (hemicellulose) and fragmentation reactions

of the pyranose ring (sugars). As the heating rate increases, the fragmentation reactions of sugars are minimized. The increase in $\mathrm{CO}$ is related to depolymerization of cellulose and lignin.

\section{Conclusions}

In this article a new reactor and methodology was presented to study sugarcane bagasse with direct impregnation of a biomass sample on a steel sheet. The film used for pyrolysis studies had an average thickness of $60 \mu \mathrm{m}$, uniform over the entire surface distribution. This allowed for the same reaction conditions each point on the film. Parametric studies across temperature and heating rate were performed with sugarcane bagasse. The results showed that beyond $100{ }^{\circ} \mathrm{C} / \mathrm{s}$, no significant changes are observed in the yields of the products due to the low thermal conductivity of the biomass [111]. At high heating rates (> $100^{\circ} \mathrm{C} / \mathrm{s}$ ), the highest yields of oligomers of sugars and lignin and lowest production of char were observed. The bio-oil obtained at low heating rates were high in water, organic acids, aldehydes, and ketones with a lower concentration of oligomers compared recovered 
with high heating rates. Overall yields obtained at high heating rates are on the same order of magnitude as those previously reported by our research group for bagasse in a fluidized bed reactor [2].

\section{Acknowledgments}

The authors pleasantly grateful to Colciencias for economic support for the development of the doctoral thesis student Jorge Montoya who is one of those responsible for this research. Dr. Garcia-Perez and Brennan Pecha want to thank the Washington State Agricultural Research Center (NIFA-Hatch-WNP00701) and the National Science Foundation (CBET1434073, CAREER CBET-1150430) for their financial support.

\section{References}

[1] A.-R.F. Drummond, I.W. Drummond, Pyrolysis of Sugar Cane Bagasse in a WireMesh Reactor, Ind. Eng. Chem. Res. 35 (1996) 1263-1268.

[2] J.I. Montoya, C. Valdés, F. Chejne, C.A. Gómez, A. Blanco, G. Marrugo, J. Osorio, E. Castillo, J. Aristóbulo, J. Acero, Bio-oil production from Colombian bagasse by fast pyrolysis in a fluidized bed: An experimental study, J. Anal. Appl. Pyrolysis. 112 (2015) 379-387.

[3] J.I. Montoya-Arbeláez, F. Chejne-Janna, M. Garcia-Pérez, Fast pyrolysis of biomass: A review of relevant aspects. Part I: Parametric study, DYNA. 82 (2015) 239-248.

[4] A. Murty Kanury, Thermal decomposition kinetics of wood pyrolysis, Combust. Flame. 18 (1972) 75-83.

[5] H.S. Heo, H.J. Park, Y.-K. Park, C. Ryu, D.J. Suh, Y.-W. Suh, J.-H. Yim, S.-S. Kim, Bio-oil production from fast pyrolysis of waste furniture sawdust in a fluidized bed., Bioresour. Technol. 101 Suppl (2010) S91-S96.

[6] H.J. Park, J.-I. Dong, J.-K. Jeon, Y.-K. Park, K.-S. Yoo, S.-S. Kim, J. Kim, S. Kim, Effects of the operating parameters on the production of bio-oil in the fast pyrolysis of Japanese larch, Chem. Eng. J. 143 (2008) 124-132.

[7] J. Lehto, A. Oasmaa, Y. Solantausta, M. Kytö, D. Chiaramonti, Fuel oil quality and combustion of fast pyrolysis bio-oils, VTT Publ. (2013) 79. 
[8] A. Oasmaa, D. Meier, Norms and standards for fast pyrolysis liquids: 1. Round robin test, J. Anal. Appl. Pyrolysis. 73 (2005) 323-334.

[9] D. Meier, B. van de Beld, A. V. Bridgwater, D.C. Elliott, A. Oasmaa, F. Preto, Stateof-the-art of fast pyrolysis in IEA bioenergy member countries, Renew. Sustain. Energy Rev. 20 (2013) 619-641.

[10] A.V. Bridgwater, Fast pyrolysis of biomass: a handbook, CPL Press, Newbury, 1999.

[11] J. Akhtar, N. Saidina Amin, A review on operating parameters for optimum liquid oil yield in biomass pyrolysis, Renew. Sustain. Energy Rev. 16 (2012) 5101-5109.

[12] F. Stankovikj, A.G. McDonald, G.L. Helms, M. Garcia_Perez, Quantification of Bio-oil Functional Groups and Evidences of the Presence of Pyrolytic Humins, Energy Fuels, (2016) 6505-6524.

[13] P.J. Dauenhauer, D.G. Vlachos, M.S. Mettler, Top ten fundamental challenges of biomass pyrolysis for biofuels, Energy Environ. Sci. 5 (2012) 7797.

[14] A.. Bridgwater, Fast Pyrolysis of Biomass: A Handbook, 3rd ed., PyNe, 2008.

[15] F. Sulaiman, N. Abdullah, Optimum conditions for maximising pyrolysis liquids of oil palm empty fruit bunches, Energy. 36 (2011) 2352-2359.

[16] A.S. Kalgo, The Development and Optimisation of a Fast Pyrolysis Process for Biooil Production, Thesis Degree of Doctor of Phylosophy, Aston University, 2011.

[17] J. Lédé, O. Authier, Characterization of biomass fast pyrolysis: Advantages and drawbacks of different possible criteria., Biomass Conv. Bioref. 1 (2011) 133-147.

[18] J. Shen, X.-S. Wang, M. Garcia-Perez, D. Mourant, M.J. Rhodes, C.-Z. Li, Effects of particle size on the fast pyrolysis of oil mallee woody biomass., Fuel. 88 (2009) $1810-1817$.

[19] A. Demirbas, Effect of initial moisture content on the yields of oily products from pyrolysis of biomass, J. Anal. Appl. Pyrolysis. 71 (2004) 803-815.

[20] J.-Y. Kim, S. Oh, H. Hwang, Y.-H. Moon, J.W. Choi, Assessment of miscanthus biomass (Miscanthus sacchariflorus) for conversion and utilization of bio-oil by fluidized bed type fast pyrolysis, Energy. (2014).

[21] M. Asadullah, R. Anisur M., A. Mohsin M., M. Abdul M., S. Borhanus M., A. Robiul M., R. Sahedur M., Jute fiber pyrolysis for bio-oil production in fluidized 
bed reactor., Bioresour. Technol. 99 (2007) 44-50.

[22] P.S. Maa, R.C. Bailie, Influence of Particle Sizes and Environmental Conditions on High Temperature Pyrolysis of Cellulosic Material-I (Theoretical), Combust. Sci. Technol. 7 (1973) 257-269.

[23] G. Kumar, R. Singh, A.K. Panda, Optimization of process for the production of biooil from eucalyptus wood, J. Fuel Chem. Technol. 38 (2010) 162-167.

[24] S. Thangalazhy-gopakumar, S. Adhikari, R.B. Gupta, S.D. Fernando, Influence of Pyrolysis Operating Conditions on Bio-Oil Components : A Microscale Study in a Pyroprobe, Energy and Fuels. 25 (2011) 1191-1199.

[25] C. Zhengng, L. D, H. Yang, R. Yan, H. Chen, D. Lee, Influence of mineral matter on pyrolysis of palm oil wastes, Combust. Flame. 146 (2006) 605-611.

[26] M. Sohrabi, M.R. Hajaligol, M. Nik-Azar, B. Dabir, Mineral matter effects in rapid pyrolysis of beech wood, Fuel Process. Technol. 51 (1997) 7-17.

[27] P.R. Patwardhan, J.A. Satrio, R.C. Brown, B.H. Shanks, Influence of inorganic salts on the primary pyrolysis products of cellulose., Bioresour. Technol. 101 (2010) 4646-4655.

[28] G. Gellerstedt, M. Kleen, Influence of inorganic species on the formation of polysaccharide and lignin degradation products in the analytical pyrolysis of pulps, J. Anal. Appl. Pyrolysis. 35 (1995) 15-41.

[29] P. De Wild, Biomass pyrolysis for chemicals, University Library Groningen, Groningen, 2011.

[30] T. Chen, C. Deng, R. Liu, Effect of selective condensation on the characterization of bio-oil from pine sawdust fast pyrolysis using a fluidized-bed reactor, Energy and Fuels. 24 (2010) 6616-6623.

[31] C.C. Chang, S.R. Wu, C.C. Lin, H.P. Wan, H.T. Lee, Fast pyrolysis of biomass in pyrolysis gas: Fractionation of pyrolysis vapors using a spray of bio-oil, in: Energy and Fuels, 2012: pp. 2962-2967.

[32] A.J. Sherwood-Pollard, Comparison of bio-oil produced in a fractionated bio-oil collection system, Mechnical Eng. (2009) 182.

[33] S. Kersten, M. Garcia-Perez, Recent developments in fast pyrolysis of lignocellulosic materials, Curr. Opin. Biotechnol. 24 (2013) 414-420. 
[34] Y. Chen, R. Bassilakis, W.W. Smith, R.M. Carangelo, M.A. Wójtowicz, Modeling the evolution of volatile species during tobacco pyrolysis, J. Anal. Appl. Pyrolysis. 66 (2003) 235-261.

[35] Z. Ma, D. Chen, J. Gu, B. Bao, Q. Zhang, Determination of pyrolysis characteristics and kinetics of palm kernel shell using TGA-FTIR and model-free integral methods, Energy Convers. Manag. 89 (2015) 251-259.

[36] Z. Ma, Q. Sun, J. Ye, Q. Yao, C. Zhao, Study on the thermal degradation behaviors and kinetics of alkali lignin for production of phenolic-rich bio-oil using TGA-FTIR and Py-GC/MS, J. Anal. Appl. Pyrolysis. 117 (2016) 116-124.

[37] P.R. Solomon, Michael A. Serio, Eric M. Suuberg, Coal pyrolysis: Experiments, kinetic rates and mechanisms, Prog. Energy Combust. Sci. 18 (1992) 133-220.

[38] X. Gong, Y. Yu, X. Gao, Y. Qiao, M. Xu, H. Wu, Formation of anhydro-sugars in the primary volatiles and solid residues from cellulose fast pyrolysis in a wire-mesh reactor, Energy and Fuels. 28 (2014) 5204-5211.

[39] E. Hoekstra, W.P.M. Van Swaaij, S.R.A. Kersten, K.J.A. Hogendoorn, Fast pyrolysis in a novel wire-mesh reactor: Decomposition of pine wood and model compounds, Chem. Eng. J. 187 (2012) 172-184.

[40] S. Zhou, B. Pecha, M. van Kuppevelt, A.G. McDonald, M. Garcia-Perez, Slow and fast pyrolysis of Douglas-fir lignin: Importance of liquid-intermediate formation on the distribution of products, Biomass and Bioenergy. 66 (2014) 398-409.

[41] N. Sonoyama, J.I. Hayashi, Characterisation of coal and biomass based on kinetic parameter distributions for pyrolysis, Fuel. 114 (2013) 206-215.

[42] A. Trubetskaya, P.A. Jensen, A.D. Jensen, M. Steibel, H. Spliethoff, P. Glarborg, Influence of fast pyrolysis conditions on yield and structural transformation of biomass chars, Fuel Process. Technol. 140 (2015) 205-214.

[43] E. Cetin, B. Moghtaderi, R. Gupta, T.. Wall, Influence of pyrolysis conditions on the structure and gasification reactivity of biomass chars, Fuel. 83 (2004) 2139-2150.

[44] Michael L. Borosont, Jack B. Howard, John P. Longwell, William A. Peters, Heterogeneous cracking of wood pyrolysis tars over fresh wood char surfaces, Energy \& Fuels. 3 (1989) 735-740.

[45] M.J. Prins, J. Lindén, Z.S. Li, R.J.M. Bastiaans, J.A. Van Oijen, M. Aldén, L.P.H. 
De Goey, Visualization of biomass pyrolysis and temperature imaging in a heatedgrid reactor, Energy and Fuels. 23 (2009) 993-1006.

[46] S.S. Liaw, V. Haber Perez, S. Zhou, O. Rodriguez-Justo, M. Garcia-Perez, PyGC/MS studies and principal component analysis to evaluate the impact of feedstock and temperature on the distribution of products during fast pyrolysis, J. Anal. Appl. Pyrolysis. 109 (2014) 140-151.

[47] M. Brebu, T. Tamminen, I. Spiridon, Thermal degradation of various lignins by TGMS/FTIR and Py-GC-MS, J. Anal. Appl. Pyrolysis. 104 (2013) 531-539.

[48] C. Lievens, D. Ci, Y. Bai, L. Ma, R. Zhang, J.Y. Chen, Q. Gai, Y. Long, X. Guo, A study of slow pyrolysis of one low rank coal via pyrolysis-GC/MS, Fuel Process. Technol. 116 (2013) 85-93.

[49] T.J. Hilbers, Z. Wang, B. Pecha, R.J.M. Westerhof, S.R.A. Kersten, M.R. PelaezSamaniego, M. Garcia-Perez, Cellulose-Lignin interactions during slow and fast pyrolysis, J. Anal. Appl. Pyrolysis. 114 (2015) 197-207.

[50] J. Montoya , B. Pecha, F. Chejne Janna, M Garcia-Perez Micro-Explosion of Liquid Intermediates During the Fast Pyrolysis of Sucrose and Organosolv Lignin, J. Anal. Appl. Pyrolysis. (In Press) doi: j.jaap.2016.10.010.

[51] F. Ronsse, D. Dalluge, W. Prins, R.C. Brown, Optimization of platinum filament micropyrolyzer for studying primary decomposition in cellulose pyrolysis, J. Anal. Appl. Pyrolysis. 95 (2012) 247-256.

[52] O. Boutin, J. Lede, G. Olalde, A. Ferriere, Solar flash pyrolysis of biomass direct measurement of the optical properties of biomass components, J. Phys. Iv. 9 (1999) $367-372$.

[53] J. Lédé, M. Ferrer, O. Boutin, Radiant flash pyrolysis of cellulose-Evidence for the formation of short life time intermediate liquid species, J. Anal. Appl. Pyrolysis. 47 (1998) 13-31.

[54] O. Authier, J. Lédé, The image furnace for studying thermal reactions involving solids. Application to wood pyrolysis and gasification, and vapours catalytic cracking, Fuel. 107 (2013) 555-569.

[55] S. Nordin, J. Nyren, E. Back, An Indication of Molten Cellulose Produced in a Laser Beam, Text. Res. J. 44 (1974) 915-917. 
[56] K. Voorhees, D.M. Blazsó, D.C. Schwarzinger, P. Carlsson, H. Lycksam, P. Gren, R. Gebart, H. Wiinikka, K. Iisa, High-speed imaging of biomass particles heated with a laser, J. Anal. Appl. Pyrolysis. 103 (2013) 278-286.

[57] T.J. Haas, M.R. Nimlos, B.S. Donohoe, Real-Time and Post-reaction Microscopic Structural Analysis of Biomass Undergoing Pyrolysis, Energy \& Fuels. 23 (2009) 3810-3817.

[58] P.D. Muley, C. Henkel, K.K. Abdollahi, C. Marculescu, D. Boldor, A critical comparison of pyrolysis of cellulose, lignin, and pine sawdust using an induction heating reactor, Energy Convers. Manag. 117 (2016) 273-280.

[59] C. Henkel, P.D. Muley, K.K. Abdollahi, C. Marculescu, D. Boldor, Pyrolysis of energy cane bagasse and invasive Chinese tallow tree (Triadica sebifera L.) biomass in an inductively heated reactor, Energy Convers. Manag. 109 (2016) 175-183.

[60] E. Hoekstra, W.P.M. van Swaaij, S.R.A. Kersten, K.J.A. Hogendoorn, Fast pyrolysis in a novel wire-mesh reactor: Design and initial results, Chem. Eng. J. 191 (2012) 45-58.

[61] M.-K. Bahng, C. Mukarakate, D.J. Robichaud, M.R. Nimlos, Current technologies for analysis of biomass thermochemical processing: a review., Anal. Chim. Acta. 651 (2009) 117-138.

[62] A.D. Paulsen, M.S. Mettler, P.J. Dauenhauer, The role of sample dimension and temperature in cellulose pyrolysis, in: Energy and Fuels, 2013: pp. 2126-2134.

[63] M. Windt, a M. Azeez, D. Meier, Novel Gas Chromatography-Mass Spectrometry Methods for Characterization of Volatile Organic Compounds and Water in Fast Pyrolysis Liquids, Energy \& Fuels. 27 (2013) 7413-7423.

[64] M. Garcia-Perez, S. Wang, J. Shen, M. Rhodes, W.J. Lee, C.Z. Li, Effects of temperature on the formation of lignin-derived oligomers during the fast pyrolysis of Mallee woody biomass, Energy and Fuels. 22 (2008) 2022-2032.

[65] X. Bai, P. Johnston, R.C. Brown, An experimental study of the competing processes of evaporation and polymerization of levoglucosan in cellulose pyrolysis, J. Anal. Appl. Pyrolysis. 99 (2013) 130-136.

[66] I. Milosavljevic, E. Suuberg, Cellulose thermal-decomposition kinetics - global mass-loss kinetics, Ind. Eng. Chem. Res. 34 (1995) 1081-1091. 
[67] M. Le Bras, J. Yvon, S. Bourbigot, V. Mamleev, The facts and hypotheses relating to the phenomenological model of cellulose pyrolysis, J. Anal. Appl. Pyrolysis. 84 (2009) 1-17.

[68] J. Lédé, J., Diebold, J.P., Peacocke, G.V.C. and Piskorz, The nature and properties of intermediate and unvaporized biomass pyrolysis materials., Dev. Thermochem. Biomass Convers. (1997) 27-42.

[69] P.Teixeira, A.R., Mooney, K.G., Kruger, J.S., Williams, C.L., Suszynski, W.J., Schmidt, L.D., Schmidt, D.P. and Dauenhauer, Aerosol generation by reactive boiling ejection of molten cellulose, Energy Environ. Sci. 4 (2011) 4306.

[70] S. Zhou, M. Garcia-Perez, B. Pecha, A.G. McDonald, R.J.M. Westerhof, Effect of particle size on the composition of lignin derived oligomers obtained by fast pyrolysis of beech wood, Fuel. 125 (2014) 15-19.

[71] D. Shen, W. Jin, J. Hu, R. Xiao, K. Luo, An overview on fast pyrolysis of the main constituents in lignocellulosic biomass to valued-added chemicals: Structures, pathways and interactions, Renew. Sustain. Energy Rev. 51 (2015) 761-774.

[72] A. Bridgwater, Fast pyrolysis processes for biomass, Renew. Sustain. Energy Rev. 4 (2000) 1-73.

[73] J. Zhang, Fast pyrolysis behavior of different celluloses and lignocellulosic biopolymer interaction during fast pyrolysis, (2012).

[74] K. Werner, L. Pommer, M. Broström, Thermal decomposition of hemicelluloses, J. Anal. Appl. Pyrolysis. 110 (2014) 130-137.

[75] M.S. Mettler, S.H. Mushrif, A.D. Paulsen, A.D. Javadekar, D.G. Vlachos, P.J. Dauenhauer, Revealing pyrolysis chemistry for biofuels production: Conversion of cellulose to furans and small oxygenates, Energy Environ. Sci. 5 (2012) 5414-5424.

[76] J. Kusters, D. Zurwerra, Supporting Information, 1 (2007) 2-7.

[77] W. Chaiwat, I. Hasegawa, T. Tani, K. Sunagawa, K. Mae, Analysis of crosslinking behavior during pyrolysis of cellulose for elucidating reaction pathway, Energy Fuels. 23 (2009) 5765-5772.

[78] C. Li, Z. Zhang, Z.K. Zhao, Direct conversion of glucose and cellulose to 5hydroxymethylfurfural in ionic liquid under microwave irradiation, Tetrahedron Lett. 50 (2009) 5403-5405. 
[79] S. Neupane, S. Adhikari, Z. Wang, A.J. Ragauskas, Y. Pu, Effect of torrefaction on biomass structure and hydrocarbon production from fast pyrolysis, Green Chem. 17 (2015) 2406-2417.

[80] Z. Wang, A.G. McDonald, R.J.M. Westerhofc, S. R.A. Kersten, Ch.M. CubaTorres, Su Had, B. Pecha, M. Garcia-Perez, Effect of cellulose crystallinity on the formation of a liquid intermediate and on product distribution during pyrolysis, $\mathrm{J}$. Anal. Appl. Pyrolysis. 100 (2013) 56-66.

[81] R. Vinu, Linda J. Broadbelt., A mechanistic model of fast pyrolysis of glucose-based carbohydrates to predict bio-oil composition., Energy Environ. Sci. 5 (2012) 98089826.

[82] R.J.. Westerhof, Refining fast pyrolysis of biomass, Thesis Degree of Doctor of Science, University of Twente, 2011.

[83] H.B. Mayes, M.W. Nolte, G.T. Beckham, B.H. Shanks, L.J. Broadbelt, The AlphaBet(a) of Glucose Pyrolysis: Computational and Experimental Investigations of 5Hydroxymethylfurfural and Levoglucosan Formation Reveal Implications for Cellulose Pyrolysis, ACS Sustain. Chem. Eng. (2014) .

[84] Y. Le Brech, L. Jia, S. Cissé, G. Mauviel, N. Brosse, A. Dufour, Mechanisms of biomass pyrolysis studied by combining a fixed bed reactor with advanced gas analysis, J. Anal. Appl. Pyrolysis. 117 (2016) 334-346.

[85] P.R. Patwardhan, Understanding the product distribution from biomass fast pyrolysis, Iowa State University, 2010. Doctoral Thesis.

[86] P.R. Patwardhan, D.L. Dalluge, B.H. Shanks, R.C. Brown, Distinguishing primary and secondary reactions of cellulose pyrolysis, Bioresour. Technol. 102 (2011) $5265-5269$.

[87] L. Sun, X. Zhang, L. Chen, B. Zhao, S. Yang, X. Xie, Comparision of catalytic fast pyrolysis of biomass to aromatic hydrocarbons over ZSM-5 and Fe/ZSM-5 catalysts, J. Anal. Appl. Pyrolysis. 121 (2016) 342-346. d

[88] X.-L. Hou, Z. Yang, K.-S. Yeung, H.N.C. Wong, Five-Membered Ring Systems: Furans and Benzofurans, 1st ed., Elsevier Ltd., 2009.

[89] S.R.G. Oudenhoven, R.J.M. Westerhof, N. Aldenkamp, D.W.F. Brilman, S.R.A. Kersten, Demineralization of wood using wood-derived acid: Towards a selective 
pyrolysis process for fuel and chemicals production, in: J. Anal. Appl. Pyrolysis, 2013: pp. 112-118.

[90] K.J.A. Hogendoorn, E. Hoekstra, S.R.A. Kersten, W.P.M. van Swaaij, Fast pyrolysis in a novel wire-mesh reactor: Design and initial results, Chem. Eng. J. 191 (2012) $45-58$.

[91] S. Zhou, N.B. Osman, H. Li, A.G. McDonald, D. Mourant, C.-Z. Li, M. GarciaPerez, Effect of sulfuric acid addition on the yield and composition of lignin derived oligomers obtained by the auger and fast pyrolysis of Douglas-fir wood, Fuel. 103 (2013) 512-523.

[92] F. Barsotti, G. Ghigo, D. Vione, Computational assessment of the fluorescence emission of phenol oligomers: A possible insight into the fluorescence properties of humic-like substances (HULIS), J. Photochem. Photobiol. A Chem. 315 (2016) 8793.

[93] T. Kotake, H. Kawamoto, S. Saka, Mechanisms for the formation of monomers and oligomers during the pyrolysis of a softwood lignin, J. Anal. Appl. Pyrolysis. 105 (2014) 309-316.

[94] X. Bai, K.H. Kim, R.C. Brown, E. Dalluge, C. Hutchinson, Y.J. Lee, D. Dalluge, Formation of phenolic oligomers during fast pyrolysis of lignin, Fuel. 128 (2014) 170-179.

[95] H. Auracher, W. Marquardt, Heat transfer characteristics and mechanisms along entire boiling curves under steady-state and transient conditions, Int. J. Heat Fluid Flow. 25 (2004) 223-242.

[96] F. Shafizadeh, T.T. Stevenson, Saccharification of douglas-fir wood by a combination of prehydrolysis and pyrolysis, J. Appl. Polym. Sci. 27 (1982) 45774585 .

[97] E. Mura, P. Massoli, C. Josset, K. Loubar, J. Bellettre, Study of the micro-explosion temperature of water in oil emulsion droplets during the Leidenfrost effect, Exp. Therm. Fluid Sci. 43 (2012) 63-70.

[98] E. Mura, P. Massoli, C. Josset, K. Loubar, J. Bellettre, Study of the micro-explosion temperature of water in oil emulsion droplets during the Leidenfrost effect, Exp. Therm. Fluid Sci. 43 (2012) 63-70. 
[99] IEA Bioenergy, Levoglucosan: Historical Developments and Current Status of Levoglucosan Production and Uses, (2015).

[100] T. Shoji, H. Kawamoto, S. Saka, Boiling point of levoglucosan and devolatilization temperatures in cellulose pyrolysis measured at different heating area temperatures, J. Anal. Appl. Pyrolysis. 109 (2014) 185-195.

[101] P.T. Williams, P.A. Horne, The role of metal salts in the pyrolysis of biomass, Renew. Energy. 4 (1994) 1-13.

[102] F. Shafizadeth, Alternative Pathways for Pyrolysis of Cellulose., ACS Div. Fuel Chem. Prepr. 28 (1983) 285-290.

[103] S. Julien, E. Chornet, R.P. Overend, Influence of acid pretreatment (H2SO4, HCl, HNO3) on reaction selectivity in the vacuum pyrolysis of cellulose, J. Anal. Appl. Pyrolysis. 27 (1993) 25-43.

[104] Z. Wang, S. Zhou, B. Pecha, R.J.M. Westerhof, M. Garcia-Perez, Effect of pyrolysis temperature and sulfuric acid during the fast pyrolysis of cellulose and douglas fir in an atmospheric pressure wire mesh reactor, Energy and Fuels. 28 (2014) 5167-5177.

[105] W.F. DeGroot, F. Shafizadeh, The influence of exchangeable cations on the carbonization of biomass, J. Anal. Appl. Pyrolysis. 6 (1984) 217-232.

[106] A. Debdoubi, A. El Amarti, E. Colacio, M.J. Blesa, L.H. Hajjaj, The effect of heating rate on yields and compositions of oil products from esparto pyrolysis, Int. J. Energy Res. 30 (2006) 1243-1250.

[107] O. Onay, Influence of pyrolysis temperature and heating rate on the production of bio-oil and char from safflower seed by pyrolysis, using a well-swept fixed-bed reactor, Fuel Process. Technol. 88 (2007) 523-531.

[108] N. Ozbay, A.E. Putun, E. Putun, Bio-oil production from rapid pyrolysis of cottonseed cake: product yields and compositions, Int. J. Energy Res. 30 (2006) 501-510.

[109] S. Wang, H. Lin, B. Ru, W. Sun, Y. Wang, Z. Luo, Comparison of the pyrolysis behavior of pyrolytic lignin and milled wood lignin by using TG-FTIR analysis, J. Anal. Appl. Pyrolysis. 108 (2014) 78-85.

[110] R.J. Evans, T.A. Milne, M.N. Soltys, Direct mass-spectrometric studies of the pyrolysis of carbonaceous fuels, J. Anal. Appl. Pyrolysis. 9 (1986) 207-236. 
[111] S.R.A. Kersten, X. Wang, W. Prins, W.P.M. van Swaaij, Biomass Pyrolysis in a Fluidized Bed Reactor. Part 1: Literature Review and Model Simulations, Ind. Eng. Chem. Res. 44 (2005) 8773-8785. 


\section{List of Figures}

Figure 1. Schematics of the hot plate reactor.

Figure 2. Power and control scheme for temperature control.

Figure 3. Verification of the temperature distribution in the central area of the steel sheet cold rod.

Figure 4. Preparation of thin film of bagasse on the steel plate.

Figure 5. Viewing the distribution of biomass particles on the steel sheet and film thickness impregnated biomass on the surface of cold steel rod.

Figure 6. (A) Uncalibrated pyrometer vs center point thermocouple temperature readings used to develop the calibration curve. (B) Calibrated pyrometer temperature vs melting points of pure metals at atmospheric pressure. Differences between the melting points and thermocouple were less than $10{ }^{\circ} \mathrm{C}$.

Figure 7. Comparison of temperature distribution in the steel sheet. (A) Temperature measurements with type $\mathrm{K}$ Thermocouple at 9 points around the central region. $\mathrm{T}_{\mathrm{f}}=400$ ${ }^{\circ} \mathrm{C}$, holding time 60s. (B) Frame 240 of sheet temperature $\mathrm{T}_{\mathrm{f}}=400{ }^{\circ} \mathrm{C}$.

Figure 8. (A) Temperature gradients at different times taken with infrared camera when the plate is heated at $5^{\circ} \mathrm{C} / \mathrm{s}$ and $600^{\circ} \mathrm{C}$.(B). Temperature distribution at different times when plate is heated at $200^{\circ} \mathrm{C} / \mathrm{s}$ and final temperature of $400^{\circ} \mathrm{C}$.

Figure 9. Comparison of records temperature on the surface of the steel sheet and on the biomass surface at $500^{\circ} \mathrm{C} / \mathrm{s}, 100^{\circ} \mathrm{C} / \mathrm{s}$ and $50^{\circ} \mathrm{C} / \mathrm{s}$ with pyrometer and thermocouple.

Figure 10. (A) Char yield versus film thickness for pyrolysis at $500^{\circ} \mathrm{C}\left(500{ }^{\circ} \mathrm{C} / \mathrm{s}, 150\right.$ mbar pressure, hold time $0 \mathrm{~s}$ ). (B) Char yield versus hold time for film thickness of $60 \pm 13$ $\mu \mathrm{m}$ at $500^{\circ} \mathrm{C}\left(500^{\circ} \mathrm{C} / \mathrm{s}, 150\right.$ mbar pressure $)$.

Figure 11. Distribution of light oxygenates analyzed by GC-MS and obtained by sugarcane bagasse pyrolysis in a hot plate reactor at $1200^{\circ} \mathrm{C} / \mathrm{s}$ and $5^{\circ} \mathrm{C} / \mathrm{s}$ and 0 holding time. (A) Water yield (wt. \%). (B) Acetoin yield (wt. \%). (C) Formic acid yield (wt. \%). (D) Acetic acid yield (wt. \%). (E) Furfuryl alcohol yield (wt. \%). (F) Glycoaldehyde yield (wt. \%). 
Figure 12. Yields of 5 member ring compounds analyzed by GC-MS obtained by sugarcane bagasse pyrolysis in a hot plate reactor at $1200{ }^{\circ} \mathrm{C} / \mathrm{s}$ and $5{ }^{\circ} \mathrm{C} / \mathrm{s}$ and 0 holding time. (A) Furan yield (wt. \%). (B) 5-HMF yield (wt. \%).

Figure 13. Distribution of aromatics products analyzed by GC-MS, and obtained by devolatilization from sugar cane bagasse (A) Naphthalene (B) Phenol (C) Pyrocatechol (D) Eugenol (E) Vanillin (F) Benzofuran.

Figure 14. A. UV-fluorescence spectra of bio-oil samples obtained by sugarcane bagasse pyrolysis in a hot plate reactor at $300^{\circ} \mathrm{C}, 400^{\circ} \mathrm{C}, 600^{\circ} \mathrm{C}$ heating rate of $500{ }^{\circ} \mathrm{C} / \mathrm{s}, 0$ holding time. B. Standards of eugenol, vanillin, 1, 2, 3-trimethoxy benzene, and levoglucosan.

Figure 15. Effect of temperature and heating rate on pyrolytic lignin yields measured by UV-Fluorescence Spectroscopy and obtained by devolatilization from sugar cane bagasse in a hot plate reactor at $1200^{\circ} \mathrm{C} / \mathrm{s}$ and $5^{\circ} \mathrm{C} / \mathrm{s}$ and 0 holding time.

Figure 16. Effect of temperature and heating rate on sugars yields measured by HPLC and obtained by devolatilization from sugarcane bagasse in a hot plate reactor at $1200^{\circ} \mathrm{C} / \mathrm{s}$ and $5{ }^{\circ} \mathrm{C} / \mathrm{s}$ and 0 holding time. The sugars yield represents cellobiosan, cellotriosan, and 1 , 4:3,6 dianhydroglucopyranose (DGP).

Figure 17. Distribution of permanent gases at different temperatures and heating rates.

Figure 18. Distribution of Char depending on the temperature and heating rate.

Figure 19. SEM visualization of morphological changes of sugarcane bagasse chars.

Figure 20. Effect of heating rate on product distribution during the pyrolysis of sugarcane bagasse in a hot plate reactor at $500^{\circ} \mathrm{C}(773 \mathrm{~K})$. 


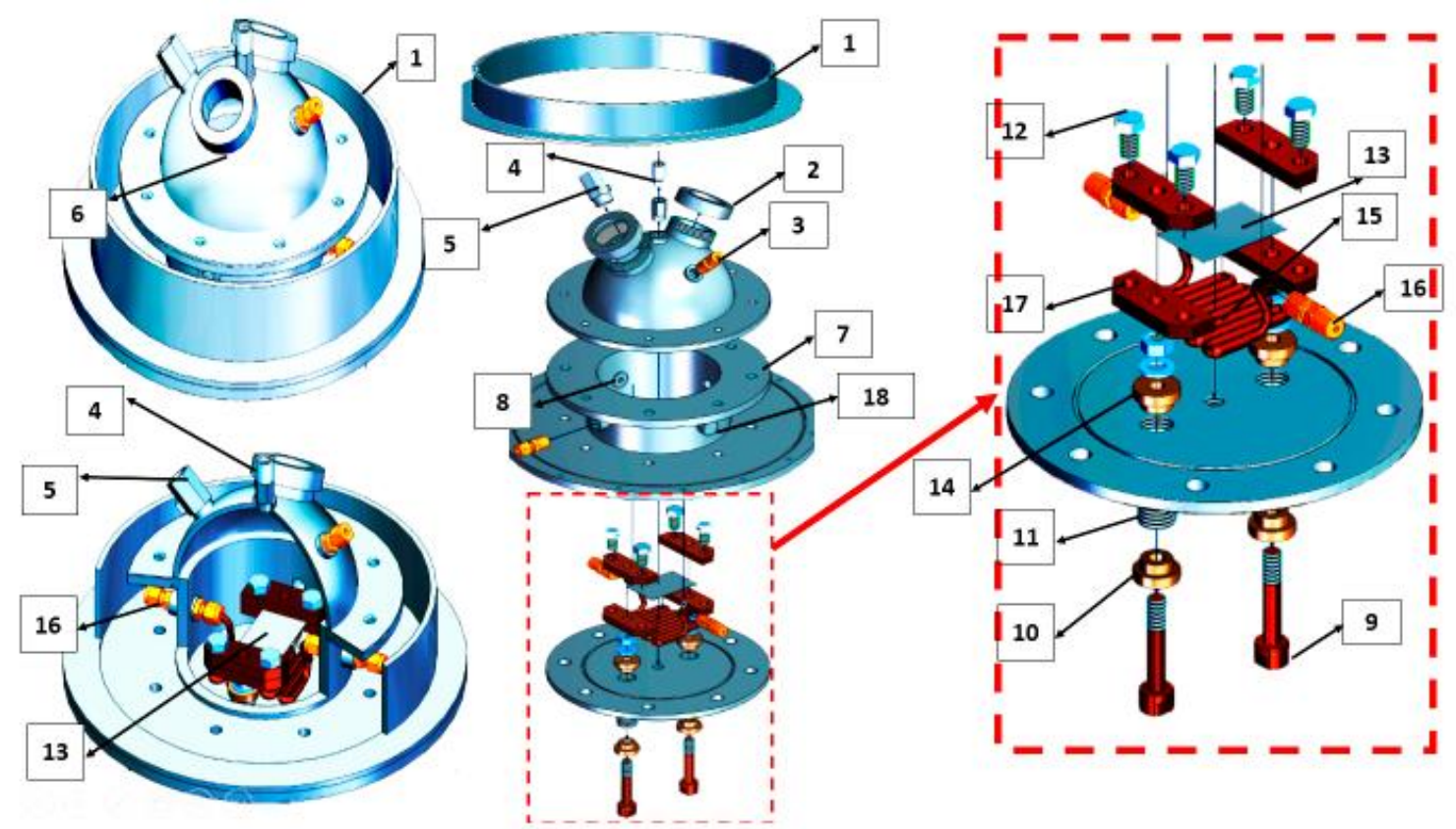

Figure 1. Schematics of the hot plate reactor (1) External housing for cooling (2) Glass window (3) Port for gas phase thermocouple (4) Pyrometer (5) Valve for sampling gases and pulling vacuum (6) Top cover reactor (7) Reaction chamber (8) Pressure sensor port (9) Copper electrode (10) Gas tight electrical feed (11) Teflon insulation (12) Screws for electrodes (13) Steel plate heated by electrodes (14) Fittings for electrode screws (15) Cold Plate (16) Fittings to adjust the plate and feed cooling or hot fluids $\left(\mathrm{CO}_{2}\right)$ (17) Copper sinks. (18) Port for carrier gas (Purge). 


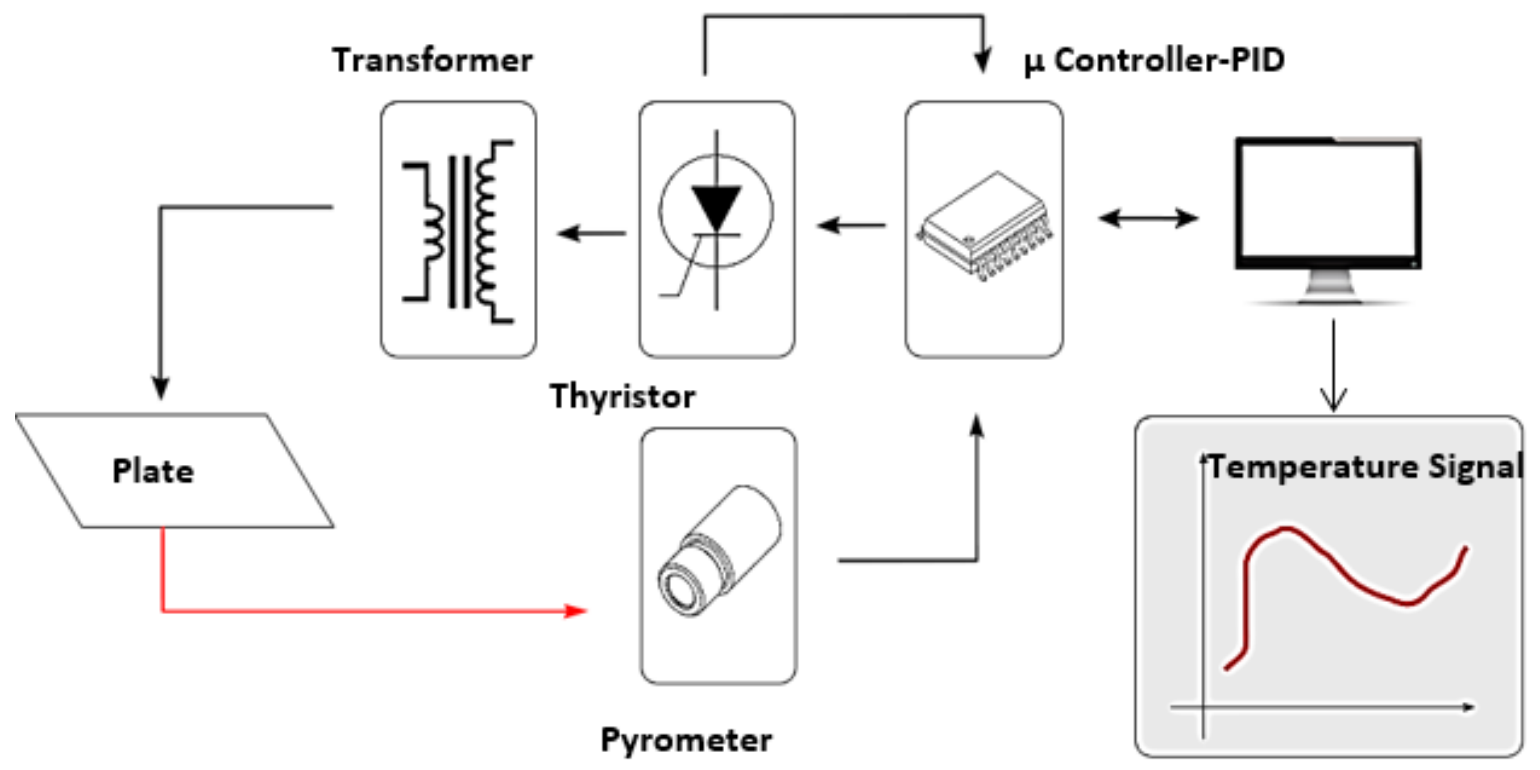

Figure 2. Power and control scheme for temperature control. 

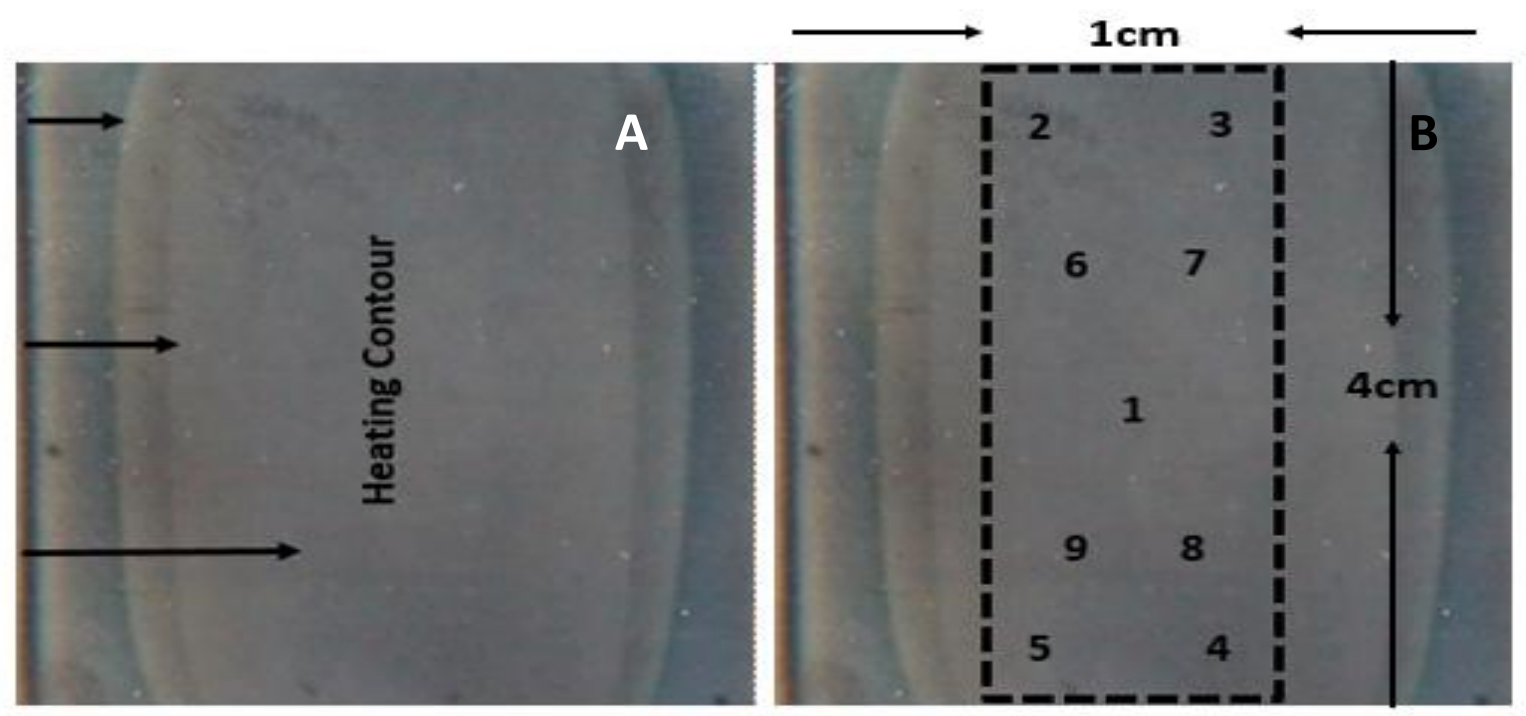

Figure 3. Verification of the temperature distribution in the central area of the steel sheet cold rod. Figure A shows what the plate looks like after heating, which illustrates that there are distinct heating regions. The pyrometer looks at point 1 (B) on the plate. The other numbered points indicate placement of the thermocouple for comparison to IR camera readings. At the end the calibration was verified by comparing melting points of 5 pure metals (indium, tin, zinc, lead, and aluminum) to the corrected temperature from the pyrometer. 

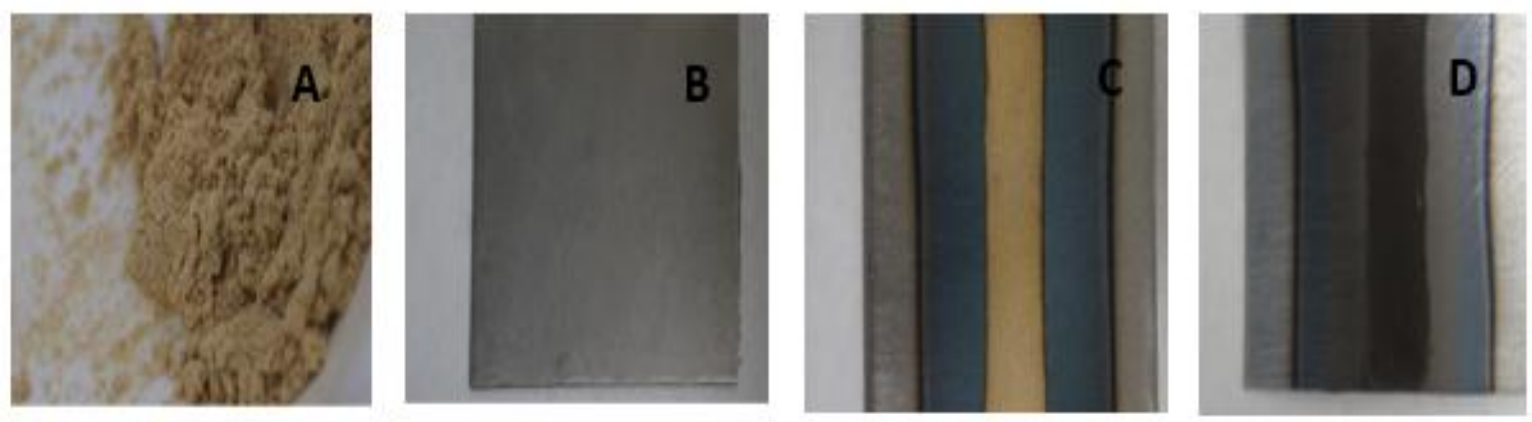

Figure 4. Preparation of thin film of bagasse on the steel plate (A) Raw ground biomass (B) Steel plate (C) Biomass impregnated on the steel plate (D) Char after pyrolysis 


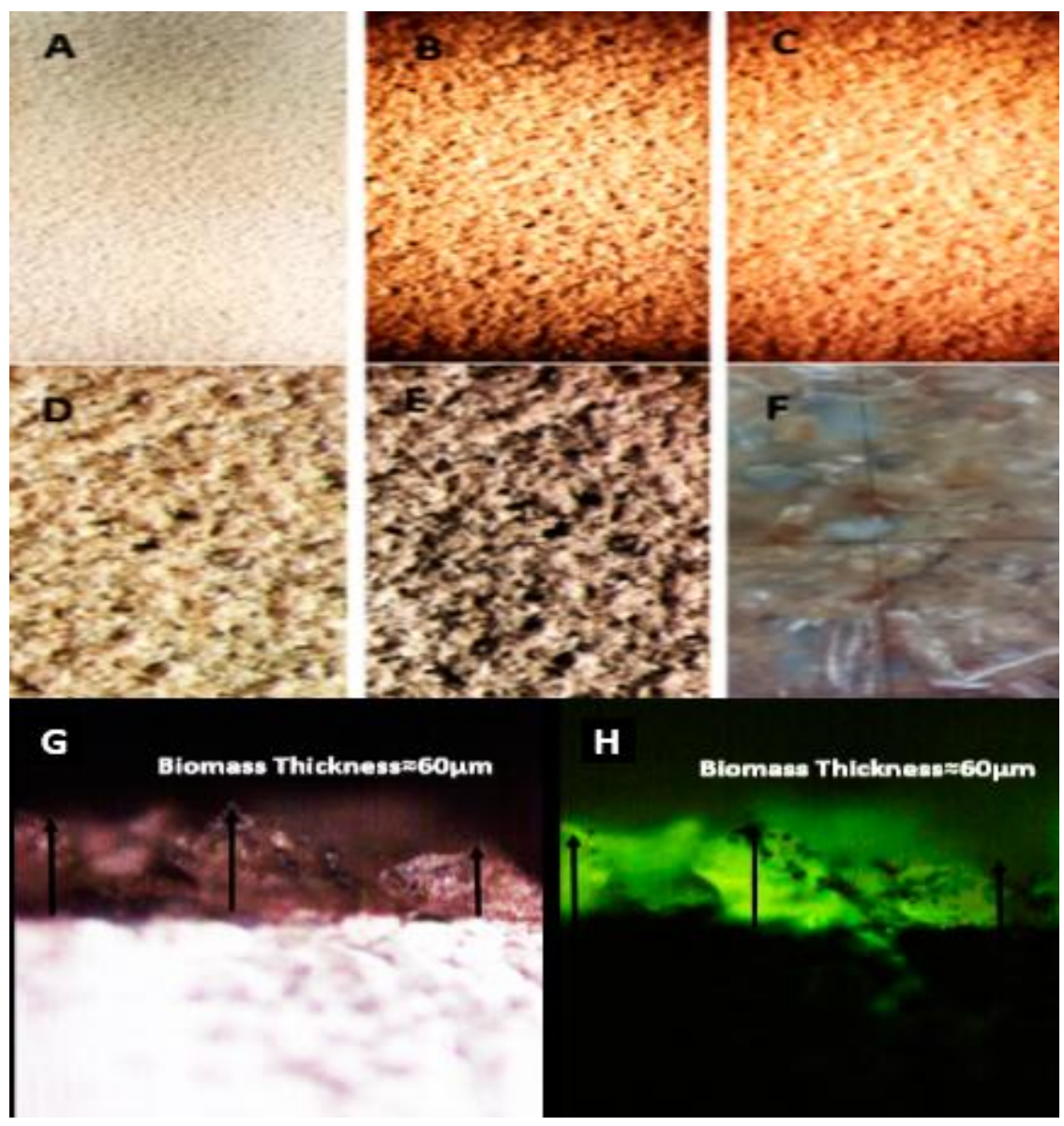

Figure 5. Viewing the distribution of biomass particles on the steel sheet. (A) $0.64 X$ (B) 1.0X (C) 1.6X (D) 2.5X (E) 4.0X (F) Increase 20X 

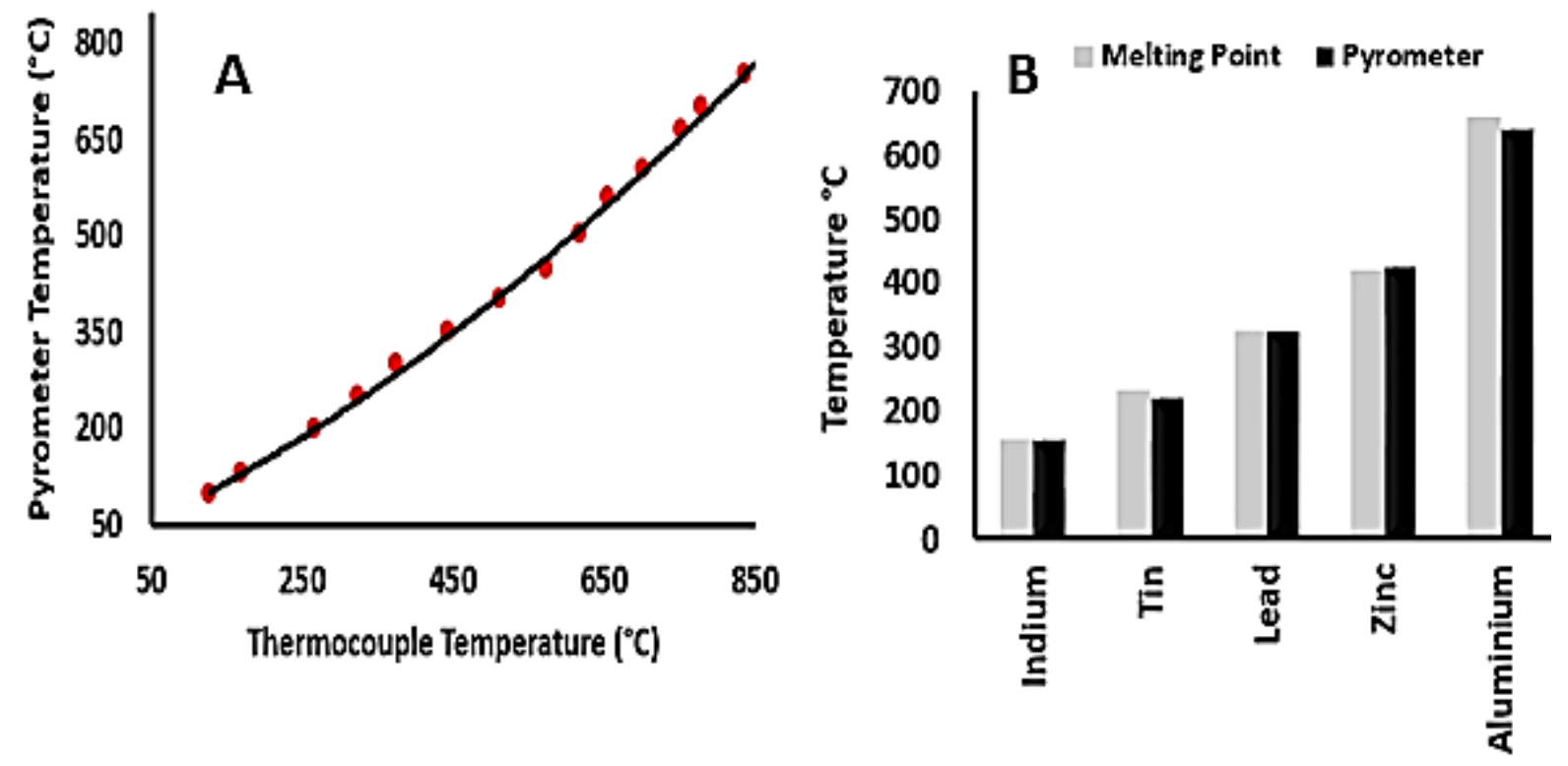

Figure 6. (A) Uncalibrated pyrometer vs centerpoint thermocouple temperature readings used to develop the calibration curve. (B) Calibrated pyrometer temperature vs melting points of pure metals at atmospheric pressure. Differences between the melting points and thermocouple were less than $10{ }^{\circ} \mathrm{C}$. 


\section{A. K-type measurements}

\section{B. Thermography-FLIR}
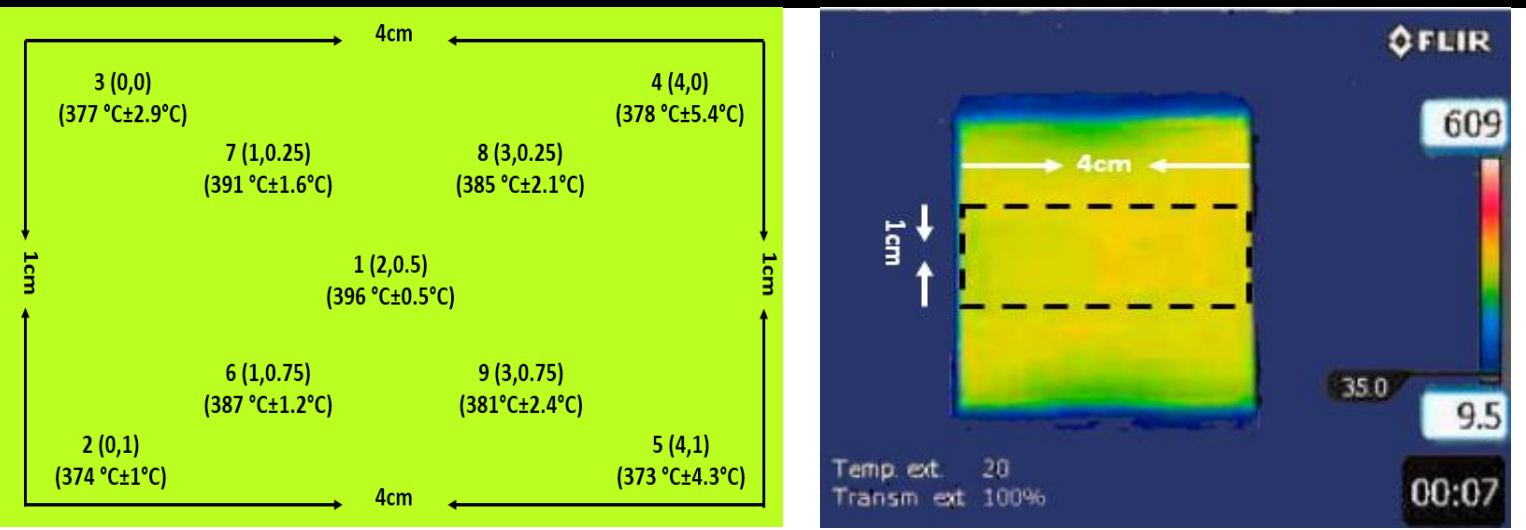

Figure 7. Comparison of temperature distribution in the steel sheet. (A) Temperature measurements with type $K$ Thermocouple at 9 points around the central region. $T_{f}=400$ ${ }^{\circ} \mathrm{C}$, holding time 60s. (B) Frame 240 of sheet temperature $\mathrm{T}_{\mathrm{f}}=400{ }^{\circ} \mathrm{C}$. 


\section{A. Temperature distribution when plate is heated at $50^{\circ} \mathrm{C} / \mathrm{s}$ and $\mathrm{Tf}=600^{\circ} \mathrm{C}$.}
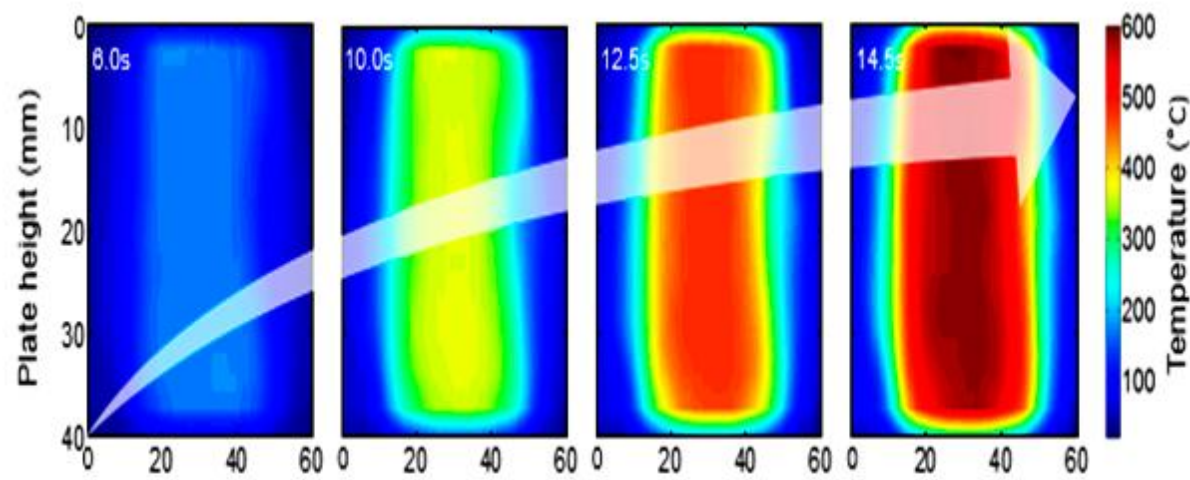

Plate width (mm)

B. Temperature distribution when plate is heated at $200^{\circ} \mathrm{C} / \mathrm{s}$ and $\mathrm{Tf}=400^{\circ} \mathrm{C}$.
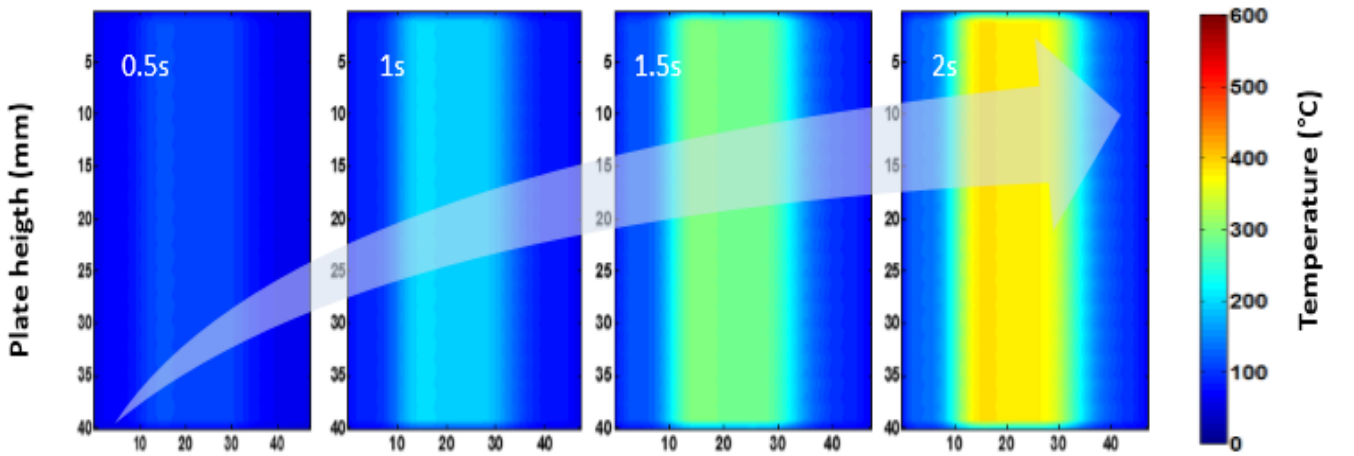

Plate width (mm)

Figure 8. A.Temperature gradients at different times taken with infrared camera when the plate is heated at $50{ }^{\circ} \mathrm{C} / \mathrm{s}$ and $600^{\circ} \mathrm{C}$. B. Temperature distribution at different times when plate is heated at $200^{\circ} \mathrm{C} / \mathrm{s}$ and final temperature of $400^{\circ} \mathrm{C}$. 


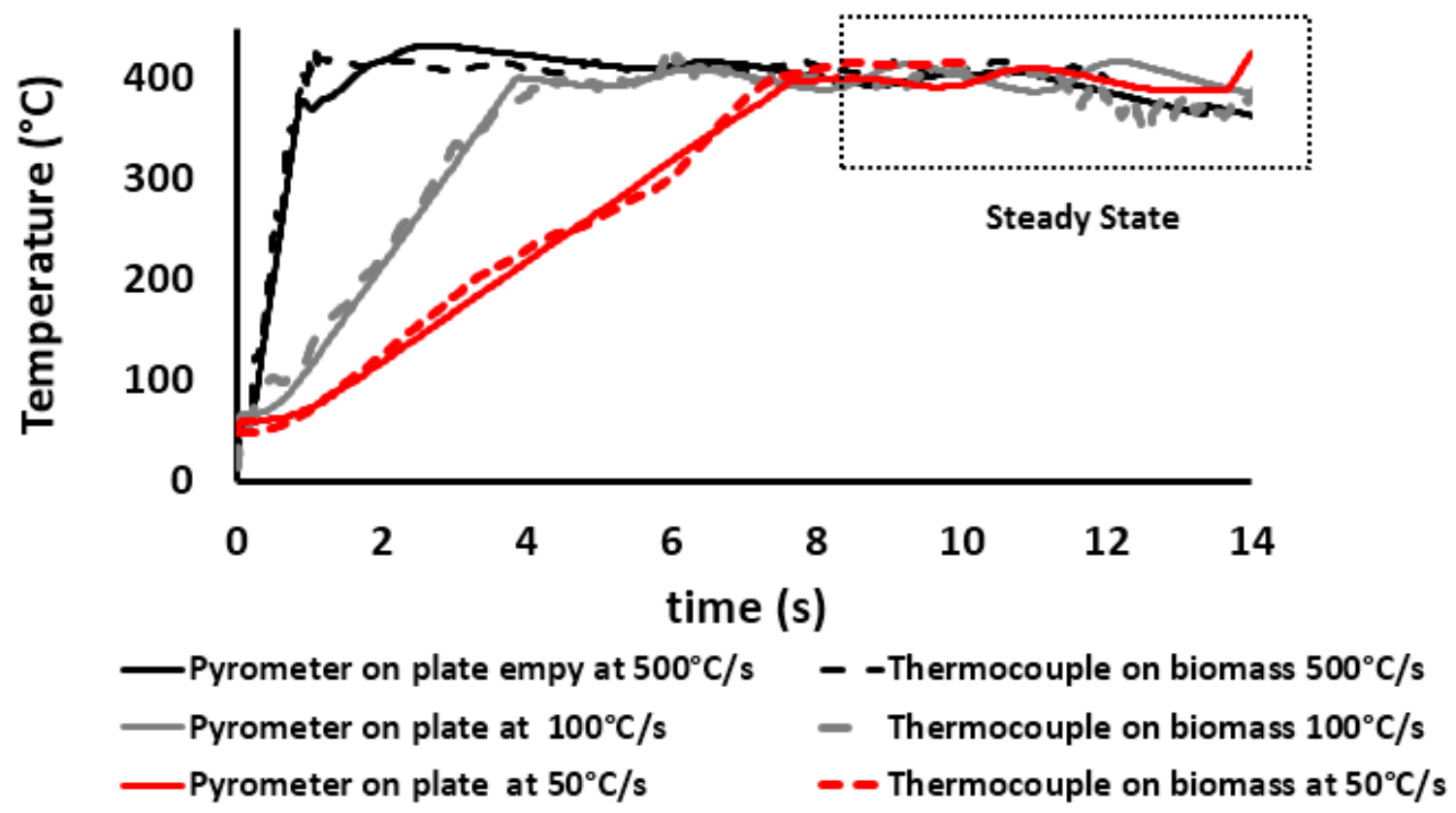

Figure 9. Comparison of records temperature on the surface of the steel sheet and on the biomass surface at $500^{\circ} \mathrm{C} / \mathrm{s}, 100^{\circ} \mathrm{C} / \mathrm{s}$ and $50^{\circ} \mathrm{C} / \mathrm{s}$ with pyrometer and thermocouple. 


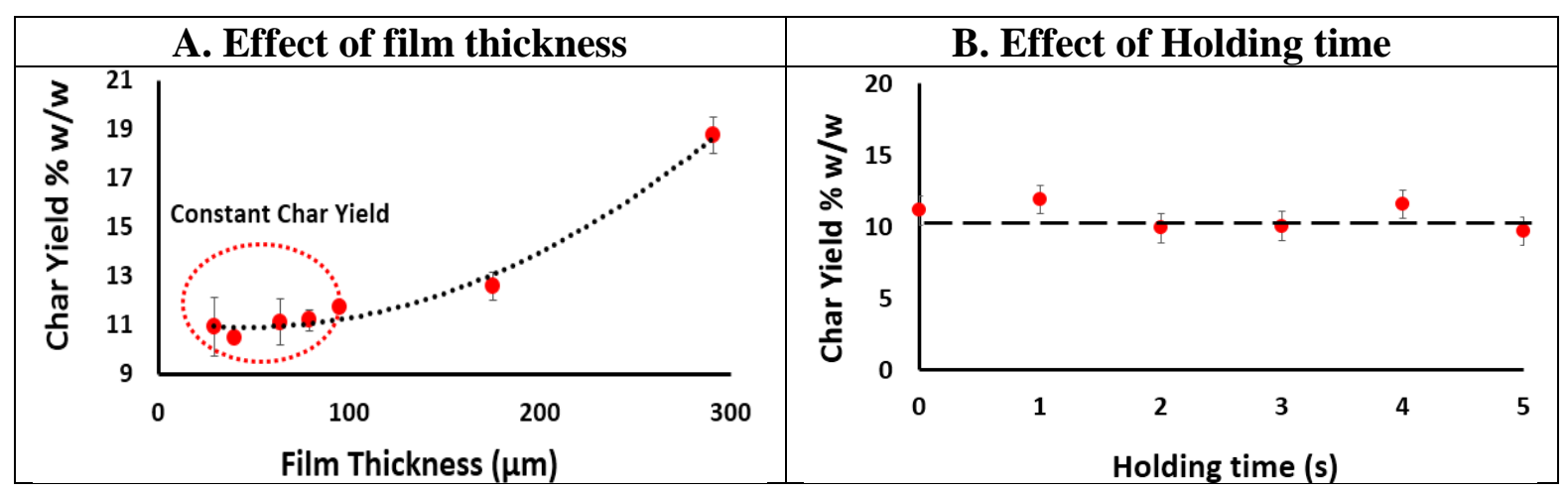

Figure 10. (A) Char yield versus film thickness for pyrolysis at $500^{\circ} \mathrm{C}\left(500{ }^{\circ} \mathrm{C} / \mathrm{s}, 150\right.$ mbar pressure, hold time $0 \mathrm{~s}$ ). (B) Char yield versus hold time for film thickness of $60 \pm 13$ $\mu \mathrm{m}$ at $500^{\circ} \mathrm{C}\left(500^{\circ} \mathrm{C} / \mathrm{s}\right.$, initial pressure $\left.150 \mathrm{mbar}\right)$. 


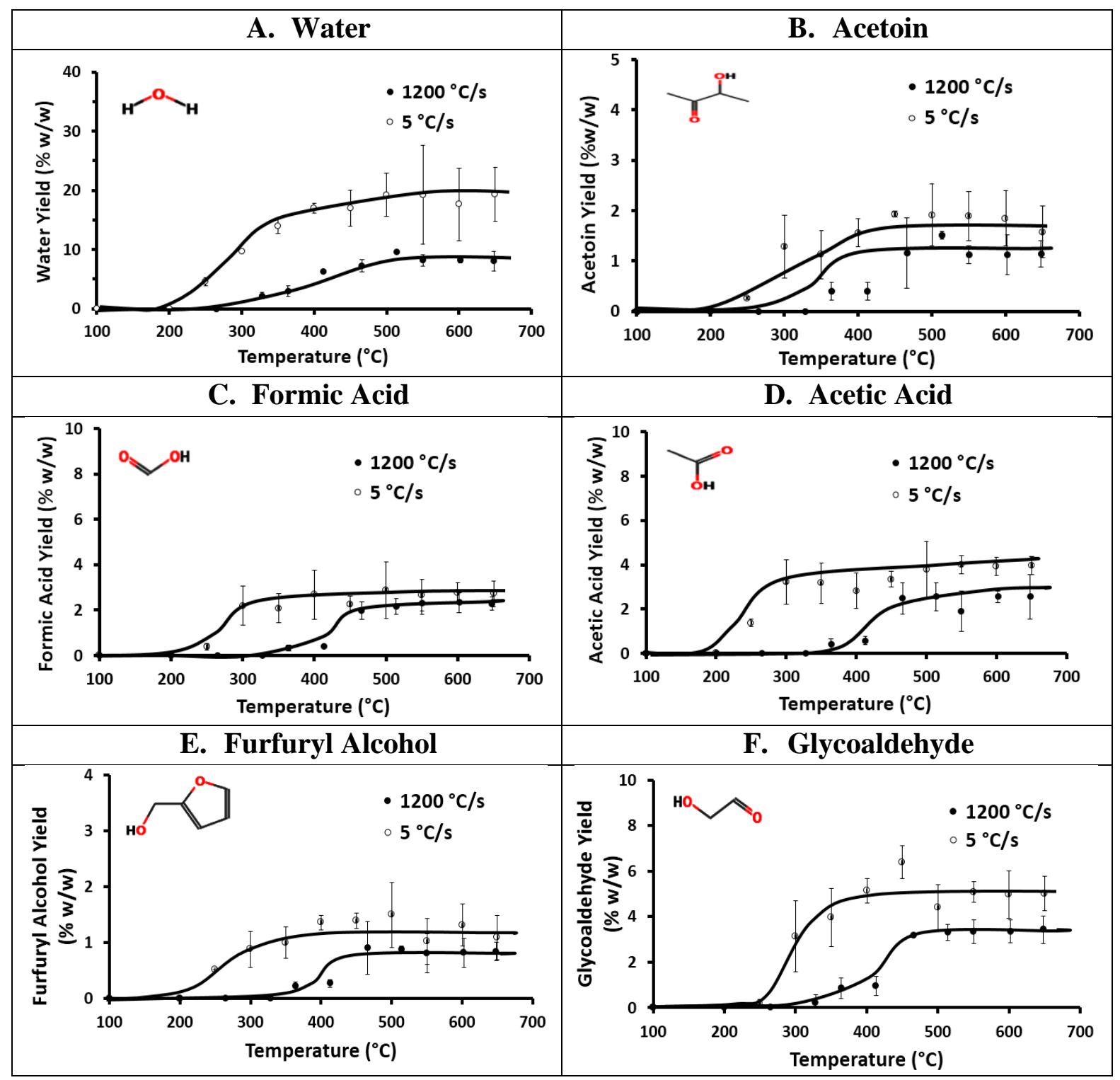

Figure 11. Distribution of light oxygenates analyzed by GC-MS and obtained by sugarcane bagasse pyrolysis in a hot plate reactor at $1200^{\circ} \mathrm{C} / \mathrm{s}$ and $5^{\circ} \mathrm{C} / \mathrm{s}$ and 0 holding time. (A) Water yield (wt. \%). (B) Acetoin yield (wt. \%). (C) Formic acid yield (wt. \%). (D) Acetic acid yield (wt. \%). (E) Furfuryl alcohol yield (wt. \%). (F) Glycoaldehyde yield (wt. \%). 


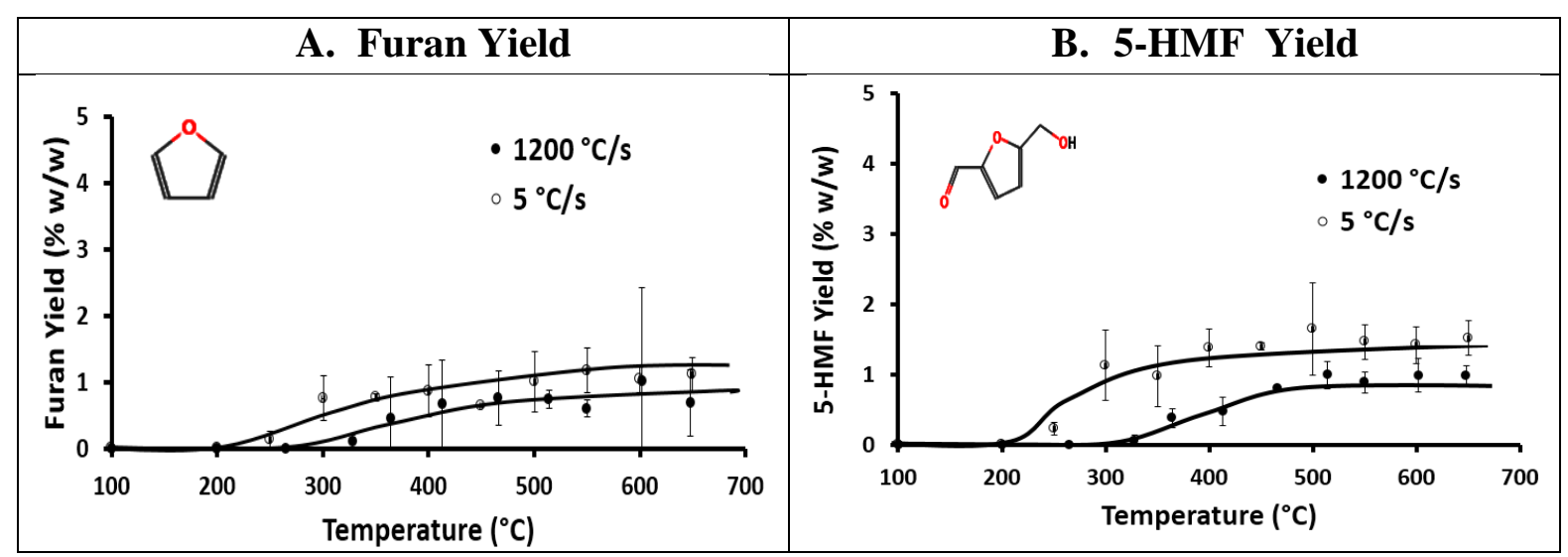

Figure 12. Yields of 5 member ring compounds analyzed by GC-MS obtained by sugarcane bagasse pyrolysis in a hot plate reactor at $1200^{\circ} \mathrm{C} / \mathrm{s}$ and $5^{\circ} \mathrm{C} / \mathrm{s}$ and 0 holding time. (A) Furan yield (wt. \%). (B) 5-HMF yield (wt. \%). 


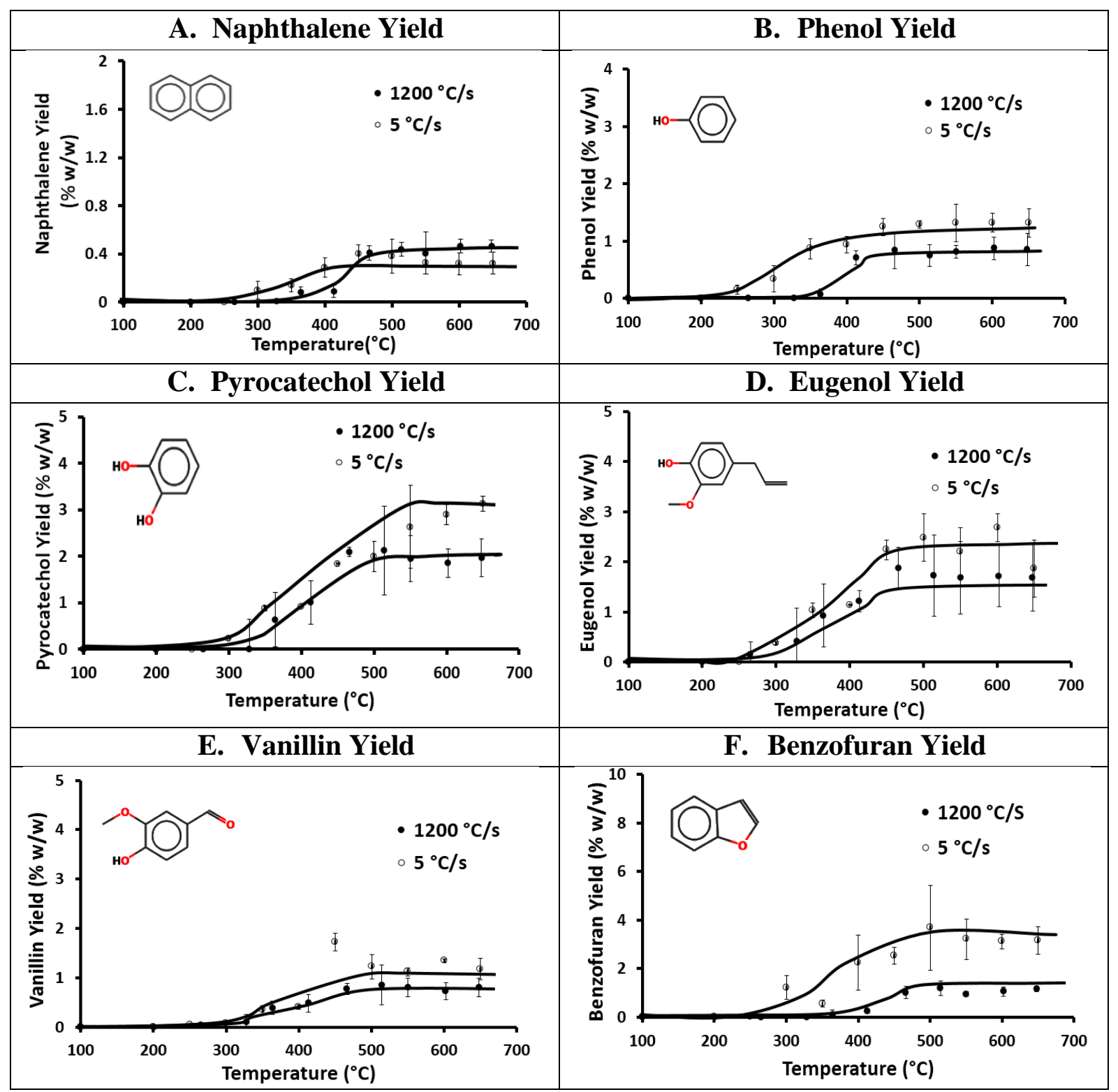

Figure 13. Distribution of aromatics products analyzed by GC-MS, and obtained by devolatilization from sugar cane bagasse (A) Naphthalene (B) Phenol (C) Pyrocatechol (D) Eugenol (E) Vanillin (F) Benzofuran. 

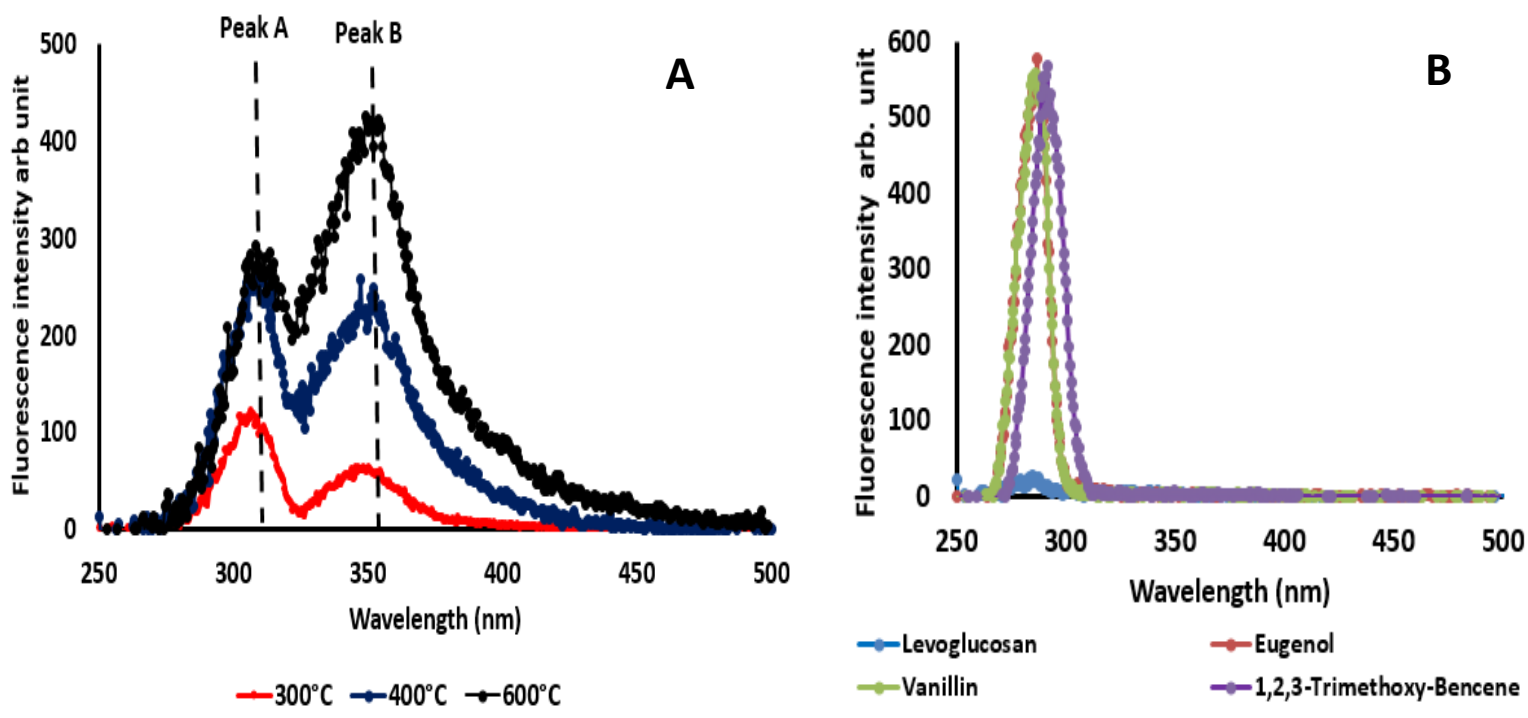

Figure 14. A. UV-fluorescence spectra of bio-oil samples obtained by sugarcane bagasse pyrolysis in a hot plate reactor at $300^{\circ} \mathrm{C}, 400^{\circ} \mathrm{C}, 600^{\circ} \mathrm{C}$ heating rate of $500{ }^{\circ} \mathrm{C} / \mathrm{s}, 0$ holding time. B. Standards of eugenol, vanillin, 1, 2, 3-trimethoxy benzene, and levoglucosan. 


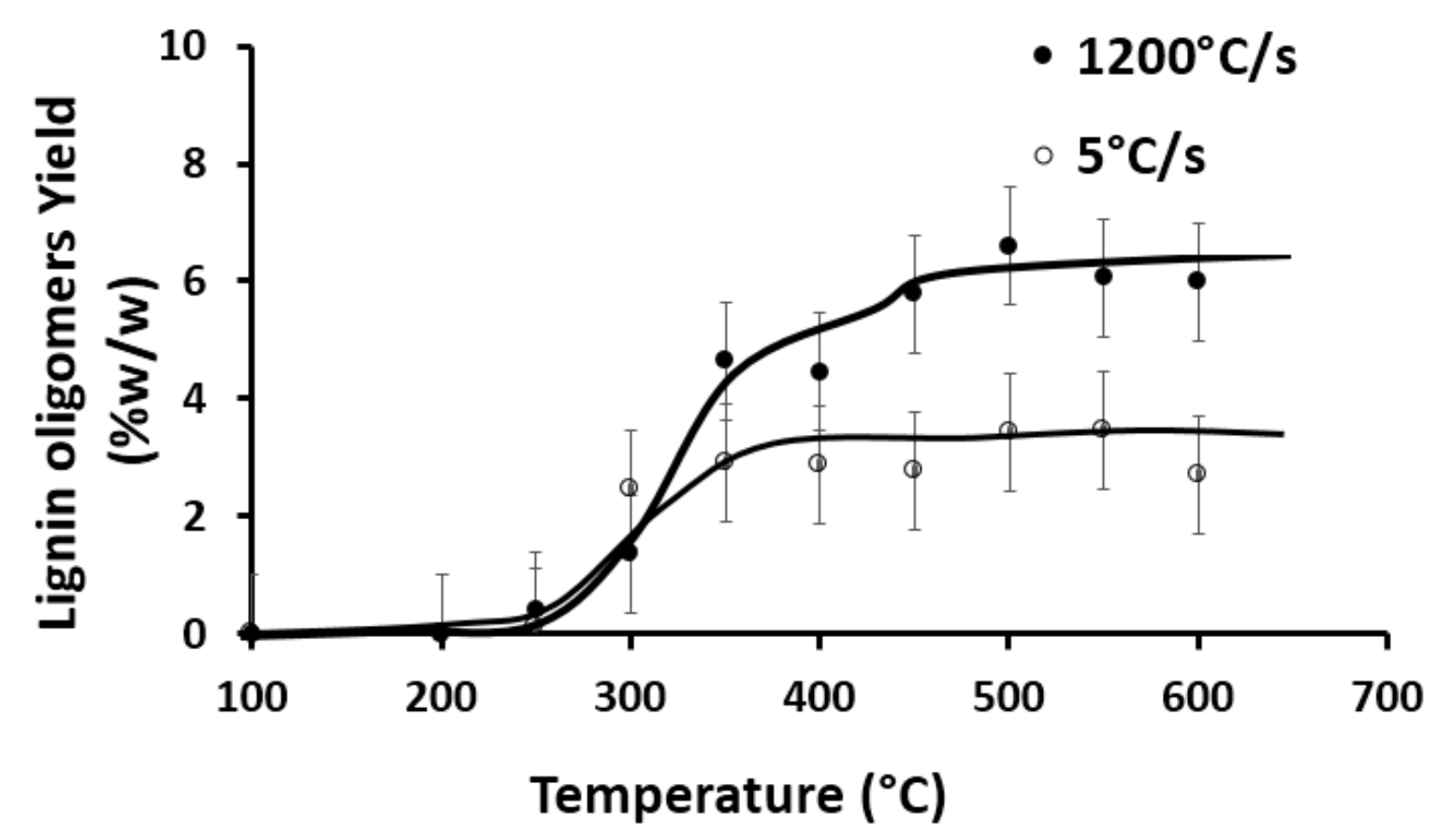

Figure 15. Effect of temperature and heating rate on pyrolytic lignin yields measured by UV-Fluorescence Spectroscopy and obtained by devolatilization from sugar cane bagasse in a hot plate reactor at $1200^{\circ} \mathrm{C} / \mathrm{s}$ and $5^{\circ} \mathrm{C} / \mathrm{s}$ and 0 holding time. 


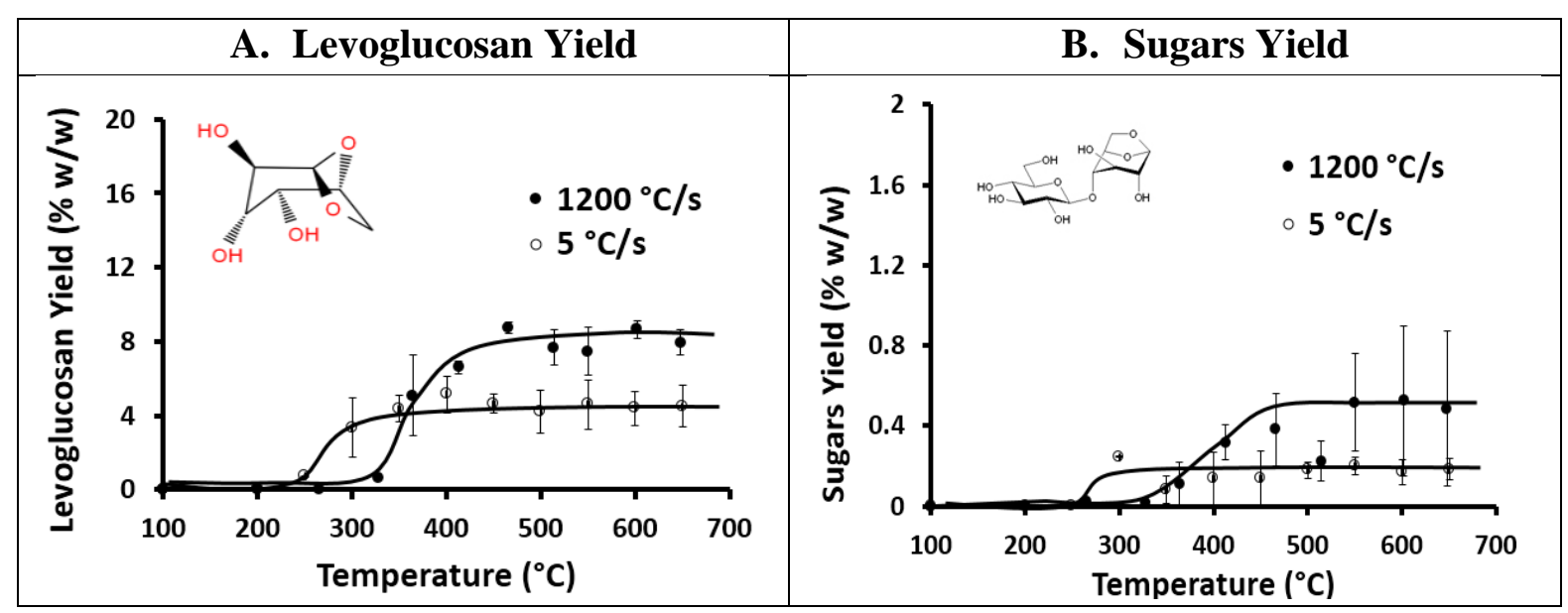

Figure 16. Effect of temperature and heating rate on sugars yields measured by HPLC and obtained by devolatilization from sugarcane bagasse in a hot plate reactor at $1200^{\circ} \mathrm{C} / \mathrm{s}$ and $5{ }^{\circ} \mathrm{C} / \mathrm{s}$ and 0 holding time. The sugars yield represents cellobiosan, cellotriosan, and 1,4:3,6 dianhydroglucopyranose (DGP). 


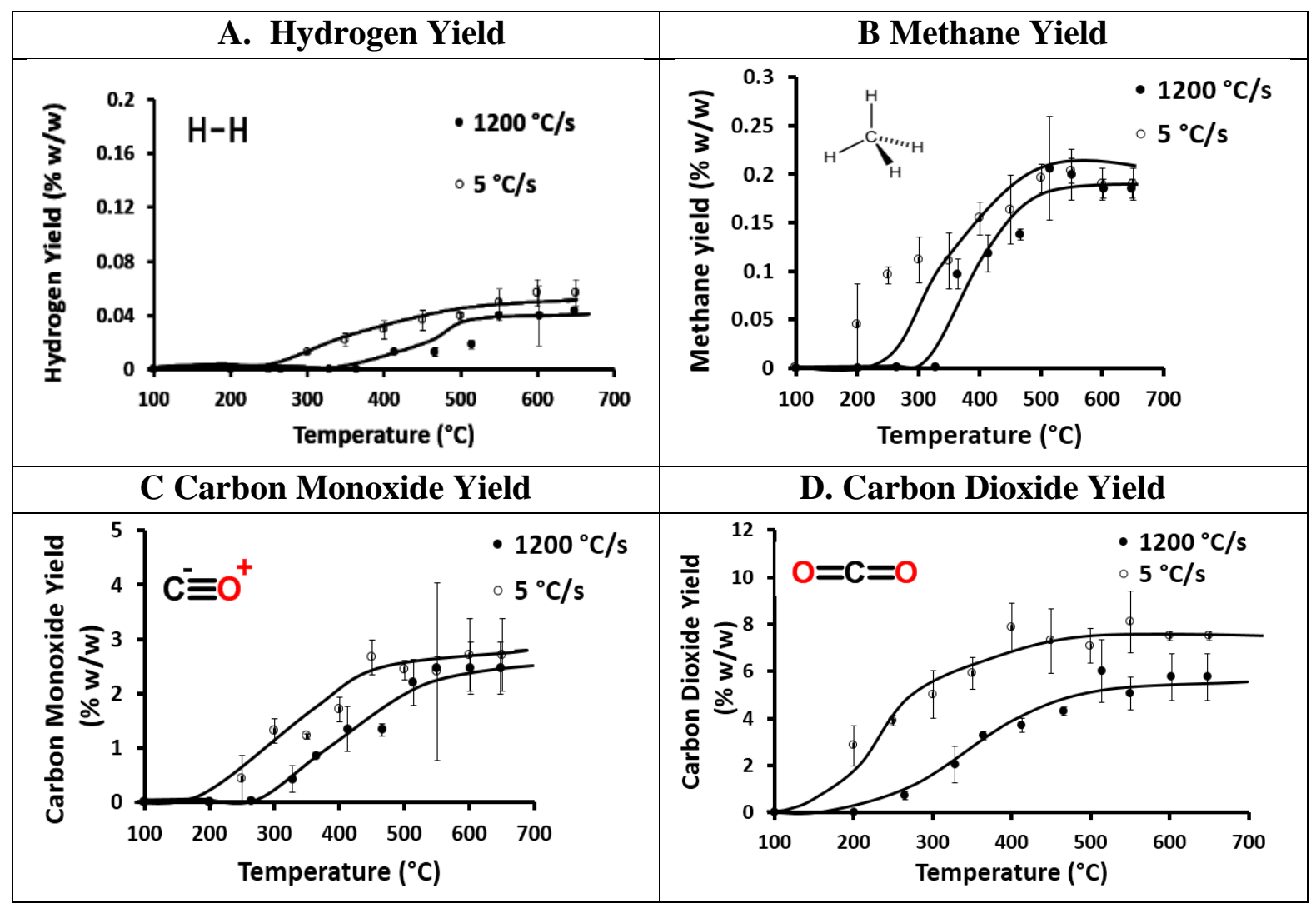

Figure 17. Distribution of permanent gases at different temperatures and heating rates 


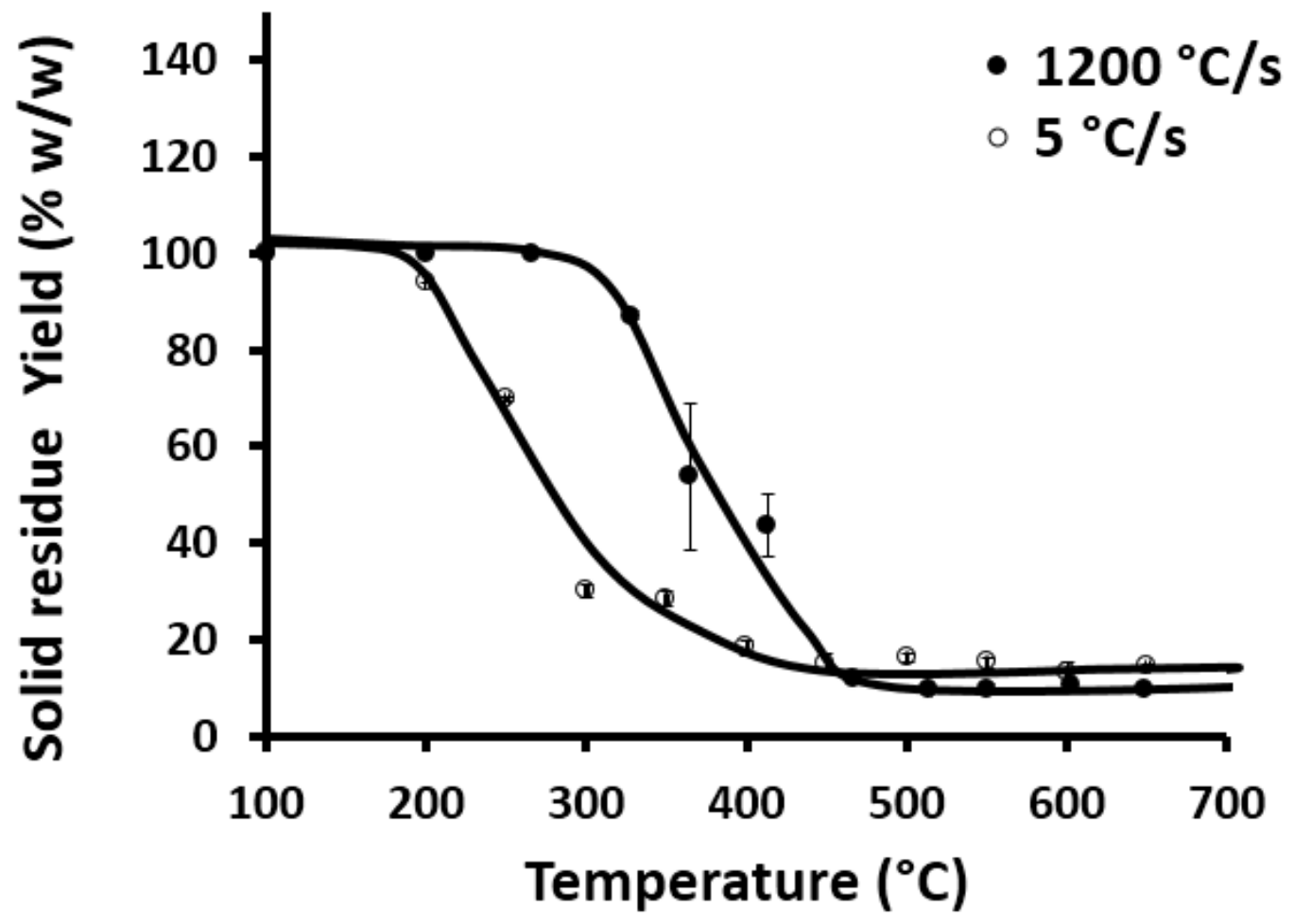

Figure 18. Distribution of Char depending on the temperature and heating rate 

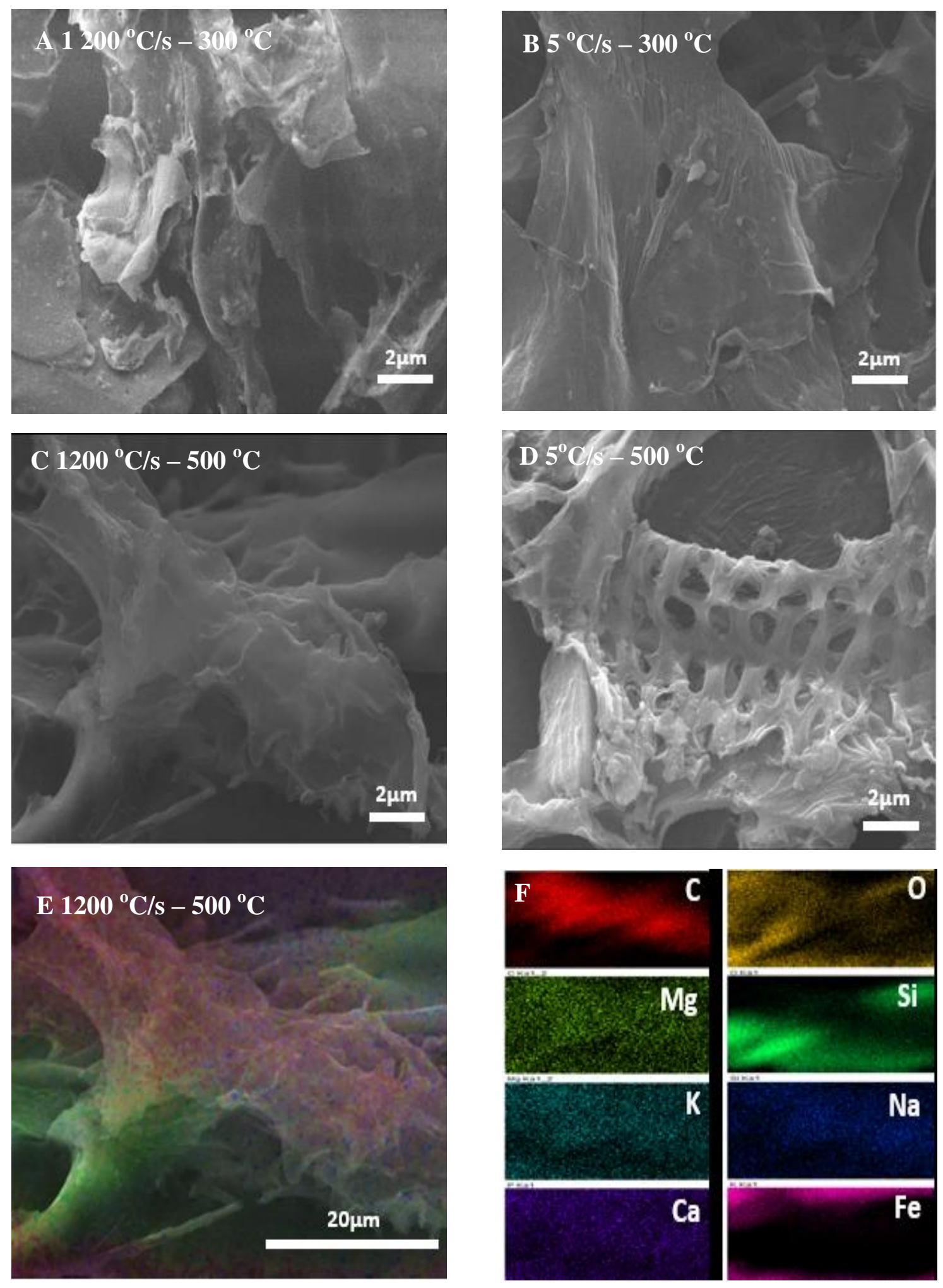

Figure 19. SEM visualization of morphological changes of sugarcane bagasse chars. 


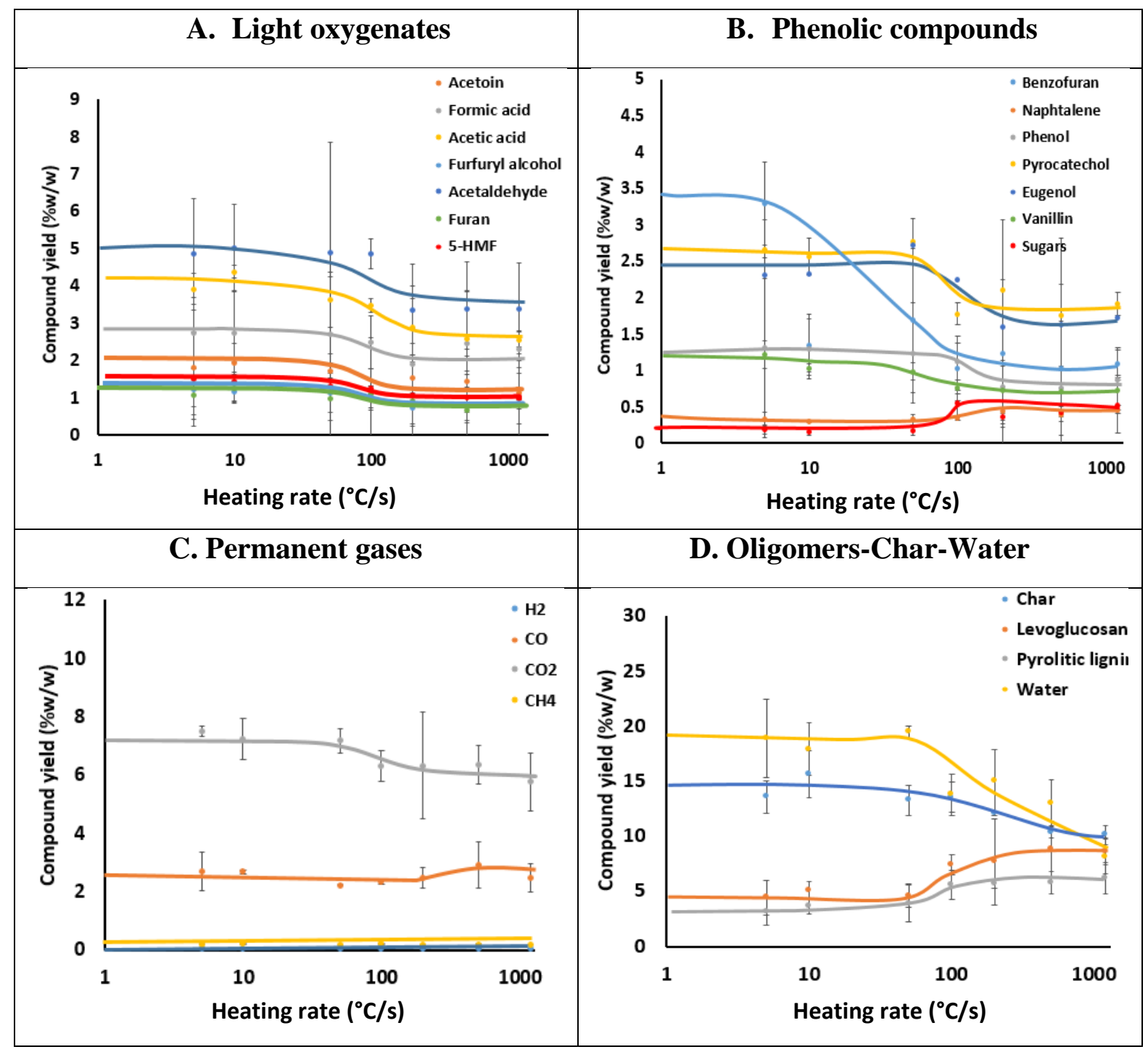

Figure 20. Effect of heating rate on product distribution during the pyrolysis of sugarcane bagasse in a hot plate reactor at $500^{\circ} \mathrm{C}(773 \mathrm{~K})$. 


\section{List of Tables:}

Table 1. Physicochemical characterization of sugar cane bagasse.

Table 2. Main Compounds identified by GC-MS, HPLC, UV-Fluorescence, $\mu$-GC 
Table 1. Physicochemical characterization of sugar cane bagasse.

\begin{tabular}{|c|c|c|c|c|c|c|c|c|c|c|}
\hline \multicolumn{11}{|c|}{ Proximate analysis (wt. \%) } \\
\hline \multicolumn{2}{|c|}{$\begin{array}{c}\text { Moisture } \\
\text { ASTM D3173-11 }\end{array}$} & \multicolumn{3}{|c|}{$\begin{array}{c}\text { Volatiles } \\
\text { ISO 562-11 }\end{array}$} & \multicolumn{3}{|c|}{$\begin{array}{c}\text { Fixed carbon } \\
\text { ASTM D31-72-13 }\end{array}$} & \multicolumn{3}{|c|}{$\begin{array}{c}\text { Ash } \\
\text { ASTM D31-74-12 }\end{array}$} \\
\hline \multicolumn{2}{|r|}{5.2} & \multicolumn{3}{|c|}{$\frac{1.50502-11}{82.6}$} & \multicolumn{3}{|c|}{8.3} & \multicolumn{3}{|c|}{3.9} \\
\hline \multicolumn{11}{|c|}{ Ultimate analysis (wt. \%) (Dry basis) } \\
\hline \multicolumn{2}{|c|}{$\begin{array}{l}\text { C } \\
\text { M D7353 }\end{array}$} & \multicolumn{2}{|c|}{$\begin{array}{l}\mathrm{H} \\
\mathrm{M} \text { D7353 }\end{array}$} & \multicolumn{2}{|c|}{$\begin{array}{l}\mathrm{N} \\
\mathrm{M} \text { D7353 }\end{array}$} & \multicolumn{3}{|c|}{$\begin{array}{c}\text { S } \\
\text { ASTM D4239- } \\
14\end{array}$} & \multicolumn{2}{|c|}{$\begin{array}{c}\mathrm{O} \\
\text { by difference }\end{array}$} \\
\hline \multicolumn{2}{|c|}{46.6} & \multicolumn{2}{|c|}{5.9} & \multicolumn{2}{|c|}{0.1} & \multicolumn{3}{|c|}{0.1} & \multicolumn{2}{|c|}{$43.5^{*}$} \\
\hline \multicolumn{11}{|c|}{ Lignocellulosic composition (wt. \%) } \\
\hline \multirow{2}{*}{\multicolumn{3}{|c|}{$\begin{array}{c}\text { Cellulose } \\
\text { NREL TP-510-42618 } \\
43.6 \\
\end{array}$}} & \multicolumn{4}{|c|}{$\begin{array}{c}\text { Hemicellulose } \\
\text { NREL TP-510-42618 }\end{array}$} & \multicolumn{4}{|c|}{$\begin{array}{c}\text { Lignin } \\
\text { NREL TP-510-42618 }\end{array}$} \\
\hline & & & \multicolumn{3}{|c|}{33.0} & & \multicolumn{4}{|c|}{21.8} \\
\hline \multicolumn{11}{|c|}{ Mineral matter composition (wt. \%) (ICP-MS, EPA 6020 and XRD) } \\
\hline $\mathrm{Na}$ & $\mathrm{Mg}$ & $\mathrm{K}$ & $\mathrm{Ca}$ & $\mathrm{Fe}$ & $\mathrm{Al}$ & $\mathrm{Mn}$ & & ln & $\mathrm{Ba}$ & $\mathrm{SiO}_{2}$ \\
\hline 0.0006 & 0.0300 & 0.2326 & 0.0489 & 0.0114 & 0.0166 & 0.0058 & & 046 & 0.0019 & 2.27 \\
\hline
\end{tabular}


Table 2. Main Compounds identified by GC-MS, HPLC, UV-Fluorescence, $\mu$-GC

\begin{tabular}{|c|c|c|c|c|c|}
\hline \multicolumn{6}{|c|}{ GC-MS } \\
\hline Peak & Compound & $\begin{array}{l}\text { time } \\
(\mathrm{min})\end{array}$ & Formula & $\mathrm{m} / \mathrm{z}$ & $\begin{array}{c}\text { MW } \\
(\mathrm{g} / \mathrm{mol})\end{array}$ \\
\hline 1 & Water & 1.045 & $\mathrm{H}_{2} \mathrm{O}$ & 18 & 18.015 \\
\hline 2 & Furan & 1.230 & $\mathrm{C}_{4} \mathrm{H}_{4} \mathrm{O}$ & 39 & 68.074 \\
\hline 3 & Formic Acid & 1.250 & $\mathrm{CH}_{2} \mathrm{O}_{2}$ & 29 & 46.025 \\
\hline 4 & Acetic Acid & 1.500 & $\mathrm{C}_{2} \mathrm{H}_{4} \mathrm{O}_{2}$ & 43 & 60.052 \\
\hline 5 & Glycoaldehyde & 1.950 & $\mathrm{C}_{2} \mathrm{H}_{4} \mathrm{O}_{2}$ & 31 & 60.052 \\
\hline 6 & Acetoin & 2.020 & $\mathrm{C}_{4} \mathrm{H}_{8} \mathrm{O}_{2}$ & 45 & 88.105 \\
\hline 7 & Furfuryl Alcohol & 3.500 & $\mathrm{C}_{5} \mathrm{H}_{6} \mathrm{O}_{2}$ & 98 & 98.099 \\
\hline 8 & Phenol & 5.290 & $\mathrm{C}_{6} \mathrm{H}_{6} \mathrm{O}$ & 94 & 94.111 \\
\hline 9 & Naphthalene & 8.415 & $\mathrm{C}_{8} \mathrm{H}_{10}$ & 128 & 128.170 \\
\hline 10 & Pyrocatechol & 8.535 & $\mathrm{C}_{6} \mathrm{H}_{6} \mathrm{O}_{2}$ & 110 & 110.110 \\
\hline 11 & Benzofuran & 8.825 & $\mathrm{C}_{8} \mathrm{H}_{6} \mathrm{O}$ & 118 & 118.132 \\
\hline 12 & 5-Hydroxymethyl-Furfural & 9.025 & $\mathrm{C}_{6} \mathrm{H}_{6} \mathrm{O}_{3}$ & 97 & 126.110 \\
\hline 13 & Eugenol & 10.835 & $\mathrm{C}_{10} \mathrm{H}_{12} \mathrm{O}_{2}$ & 164 & 164.201 \\
\hline 14 & Vanillin & 11.395 & $\mathrm{C}_{8} \mathrm{H}_{8} \mathrm{O}_{3}$ & 151 & 152.147 \\
\hline 15 & Levoglucosan & 12.500 & $\mathrm{C}_{6} \mathrm{H}_{10} \mathrm{O}_{5}$ & 60 & 162.140 \\
\hline \multicolumn{6}{|c|}{$\mu-G C$} \\
\hline 1 & Hydrogen & 0.200 & $\mathrm{H}_{2}$ & & 2.016 \\
\hline 2 & Carbon Dioxide & 0.440 & $\mathrm{CO}_{2}$ & & 44.010 \\
\hline 3 & Carbon Monoxide & 1.125 & $\mathrm{CO}$ & & 28.010 \\
\hline 4 & Methane & 1.575 & $\mathrm{CH}_{4}$ & & 16.040 \\
\hline \multicolumn{6}{|c|}{ HPLC } \\
\hline 1 & Cellotriosan & 10.948 & $\mathrm{C}_{18} \mathrm{H}_{30} \mathrm{O}_{15}$ & & 486.420 \\
\hline 2 & Cellobiosan & 13.855 & $\mathrm{C}_{12} \mathrm{H}_{20} \mathrm{O}_{10}$ & & 324.280 \\
\hline 3 & 1,6 Anhydro $\beta$-D-Glucofuranose & 16.248 & $\mathrm{C}_{6} \mathrm{H}_{10} \mathrm{O}_{5}$ & & 162.140 \\
\hline 4 & $\begin{array}{l}\text { 1,4:3,6 Dianhydro } \alpha \text {-D-Gluco } \\
\text { Pyranose }\end{array}$ & 20.005 & $\mathrm{C}_{6} \mathrm{H}_{8} \mathrm{O}_{4}$ & & 144.130 \\
\hline 5 & Levoglucosenone & 21.865 & $\mathrm{C}_{6} \mathrm{H}_{6} \mathrm{O}_{3}$ & & 126.110 \\
\hline \multicolumn{6}{|c|}{ UV-Fluorescence } \\
\hline 1 & Lignin Oligomers & 300 & $80 \mathrm{~nm}$ & & \\
\hline
\end{tabular}

